\title{
Does the Use of Dihydroartemisinin-Piperaquine in Treating Patients with Uncomplicated falciparum Malaria Reduce the Risk for Recurrent New falciparum Infection More Than Artemether-Lumefantrine?
}

\author{
Wisdom Akpaloo ${ }^{1,2}$ and Edward Purssell ${ }^{2}$ \\ ${ }^{1}$ AngloGold Ashanti Hospital, P.O. Box 10, Obuasi, Ghana \\ ${ }^{2}$ Florence Nightingale School of Nursing and Midwifery, King's College London, London SE1 8WA, UK
}

Correspondence should be addressed to Wisdom Akpaloo; wiskof84@gmail.com

Received 8 February 2014; Revised 4 May 2014; Accepted 18 May 2014; Published 19 June 2014

Academic Editor: Donatella Taramelli

Copyright (c) 2014 W. Akpaloo and E. Purssell. This is an open access article distributed under the Creative Commons Attribution License, which permits unrestricted use, distribution, and reproduction in any medium, provided the original work is properly cited.

\begin{abstract}
Malaria contributes significantly to the global disease burden. The World Health Organization recommended the use of artemisininbased combination therapies (ACTs) for treatment of uncomplicated falciparum malaria a decade ago in response to problems of drug resistance. This review compared two of the ACTs-Dihydroartemisinin-Piperaquine (DP) and Artemether-Lumefantrine (AL) to provide evidence which one has the ability to offer superior posttreatment prophylaxis at 28 and 42 days posttreatment. Four databases (MEDLINE, EMBASE, Cochrane Database and Global Health) were searched on June 2, 2013 and a total of seven randomized controlled trials conducted in sub-Sahara Africa were included. Results involving 2, 340 participants indicates that reduction in risk for recurrent new falciparum infections (RNIs) was 79\% at day 28 in favour of DP [RR, 0.21; 95\% CI: 0.14 to 0.32 , $P<0.001$ ], and at day 42 was $44 \%$ favouring DP [RR, $0.56 ; 95 \%$ CI: 0.34 to $0.90 ; P=0.02$ ]. No significant difference was seen in treatment failure rates between the two drugs at days 28 and 42. It is concluded that use of DP offers superior posttreatment prophylaxis compared to AL in the study areas. Hence DP can help reduce malaria cases in such areas more than AL.
\end{abstract}

\section{Introduction}

Malaria has attracted global attention as one of the world's leading major diseases due to its high morbidity and mortality. The World Health Organization (WHO) estimated that about 3.3 billion people are at risk of malaria because they live in malaria endemic areas [1] and about 300500 million malaria cases are reported globally each year [2]. Malaria is also responsible for almost a million deaths yearly $[2,3]$. The disease is strongly associated with poverty because it disengages patients from carrying out meaningful economic activities during attacks and it also consumes huge expenditure budgets. It is estimated that as high as $40 \%$ of public health expenditure is spent on malaria alone in endemic countries [4]. Malaria is a febrile disease caused by parasites of the genus Plasmodium which are transmitted to susceptible persons through the bite of infected female Anopheles mosquitoes.

The burden of malaria is greatest in sub-Sahara Africa where approximately $80 \%$ of the global malaria cases as well as $90 \%$ of fatalities occur [1]. Children less than 5 years are the most severely affected accounting for $86 \%$ of the deaths [5]. To this extent, malaria has been recognized as an impediment to achievement of the United Nation's Millennium Development Goal (MDG) 4 which targets at the reduction of child mortality [6]. Therefore, without effective prevention and control of malaria (which is the MDG 6), it will be difficult to achieve the MDG 4 .

In order to minimise the effects of malaria, prompt clinical diagnosis and effective treatment are needed [7-9] beside the preventive measures such as use of insecticide treated nets (ITN) and indoor residual spraying (IRS) with 
TABle 1: Plasma half-lives $\left(T_{1 / 2}\right)$ of drugs used in some common ACTs.

\begin{tabular}{lcc}
\hline Antimalarial drug & $\begin{array}{c}T_{1 / 2}{ }^{1} \text { of artemisinin } \\
\text { derivative }\end{array}$ & $\begin{array}{c}T_{1 / 2} \text { of partner } \\
\text { drug }\end{array}$ \\
\hline $\begin{array}{l}\text { Artemether- } \\
\text { Lumefantrine } \\
\text { (AL) }\end{array}$ & $4-5$ days \\
$\begin{array}{l}\text { Artesunate- } \\
\text { Amodiaquine } \\
\text { (AMQ) }\end{array}$ & $9-18$ days \\
$\begin{array}{l}\text { Dihydroartemisinin- } \\
\text { Piperaquine } \\
\text { (DP) }\end{array}$ & $<1 \mathrm{hr}$ \\
$\begin{array}{l}{ }^{1} T_{1 / 2} \text { (half-life): it is the length of time required for half of the concentration } \\
\text { of the ACT drugs in the body of a patient to be eliminated. }\end{array}$
\end{tabular}

insecticides. However, prompt malaria treatment efforts are being threatened by widespread problem of antimalaria drug resistance $[1,6,10]$. For instance, Plasmodium falciparum had developed resistance to chloroquine which was the most affordable and readily available antimalaria drug in Africa [10]. As a result, the WHO recommended artemisinin-based combination therapy (ACT) for treatment of uncomplicated falciparum malaria $[11,12]$. This type of treatment makes use of combination of an artemisinin derivative with a partner drug. The artemisinin derivatives are fast acting drugs capable of rapid clearing of the falciparum parasites during treatment $[12,13]$ but have short half-lives which render them almost unsuitable for use as single therapeutic drugs because of risk for drug resistance which increases as plasma levels fall [14].

Following the WHO recommendation, most sub-Sahara African countries have changed their antimalaria drug policy to the use of the ACTs [15]. Artemether-Lumefantrine (AL) is one of the ACTs commonly used as first-line drug for treatment of uncomplicated falciparum malaria in the sub-Sahara African countries. Another ACTDihydroartemisinin-Piperaquine (DP) - was also recently recommended by the WHO for use [12]. However, DP is not widely used in sub-Sahara Africa compared to the use of AL [1]. The half-lives of the partner drugs in the ACTs vary across the different ACT drugs available-see Table 1 [14]. The partner drug in AL, Lumefantrine, has a half-life of $\sim 5$ days while the partner drug in DP, Piperaquine, has a half-life of $\sim 5$ weeks, the longest of all the ACTS. As a result, it is being speculated that DP could be the ACT with greatest posttreatment prophylactic efficacy due to the longer half-life and sustained plasma levels of Piperaquine compared to other ACTs such as AL [16]. However, little is known about the relative extent to which these two ACTs exert their prophylactic effect after treatment. It is not yet clear whether the sheer longer half-life of Piperaquine in DP could translate into a better prophylaxis and to what extent compared to Lumefantrine in AL. No review had comprehensively compared these two ACTs head-to-head to determine their relative prophylactic effectiveness. Earlier reviews $[17,18]$ had not explored prophylaxis specifically in detail.
Olliaro and colleagues found that recurrent new infections (RNIs) were associated with higher risk for development of symptomatic disease (malaria) than recrudescence parasitaemia [19]. In contrast, other researchers had found that rather recrudescence parasitaemia carries greater risk for worse haematological outcome for patients [20]. These two studies were not conducted on ACTs but the most important issue at stake here is that both recrudescence and new infections are associated with various risks to patients; hence, prevention of their occurrence should be of much concern. This current review aimed at synthesizing available primary studies conducted in sub-Sahara Africa to determine whether use of DP reduces incidence of new falciparum infections (RNIs) and treatment failure more than use of AL within 28 and 42 days after treatment. A clear knowledge in this regard would offer a better guidance to country antimalaria drug policies in sub-Sahara Africa. The main review question is, "Does the use of DP in treating uncomplicated falciparum malaria reduce the risk for recurrent new falciparum infections and treatment failure more than AL?" The review tested the null hypothesis that there is no difference between the two drugs.

\section{Materials and Methods}

2.1. Definition of Terms. For purposes of this review, "recurrent new falciparum infection" (RNI) is defined as new infections which patients acquired by day 28 or 42 following treatment for uncomplicated falciparum malaria using DP or AL. "total treatment failure" (TTF) refers to recrudescence recorded by day 28 or day 42 (Tables 5 and 6) after treatment, where recrudescence refers to the "old" or the original parasites for which the antimalaria treatment was initiated but could not be cleared by the antimalaria drug and the disease (symptomatic malaria) has returned. The new infections must have been differentiated from the "old" infections in the primary studies by use of polymerase chain reaction (PCR). Prophylactic effectiveness used in this review refers to the ability of the ACT drug (DP or AL) to prevent the occurrence of new falciparum infections within 28 or 42 days after treatment with either drug (Tables 7 and 8).

2.2. Inclusion and Exclusion Criteria. Studies were included in the review if they were randomized controlled trial (RCT) conducted in sub-Sahara Africa and had compared the two drugs (DP and AL) head-to-head for treatment of uncomplicated falciparum monoinfections only. All patients recruited for the primary studies must have been confirmed through laboratory investigation to be infected with $P$. falciparum only and must not have shown signs of severe malaria or be suffering from co-febrile infection at the time of enrolment. The trial must be conducted according to the WHO protocols for antimalaria drug efficacy study. Studies which included pregnant women were excluded.

2.3. Database Search Strategy. An electronic search to locate relevant published studies was conducted in four main databases, namely, EMBASE, MEDLINE, Cochrane Library, 
TABLE 2: The electronic search strategy.

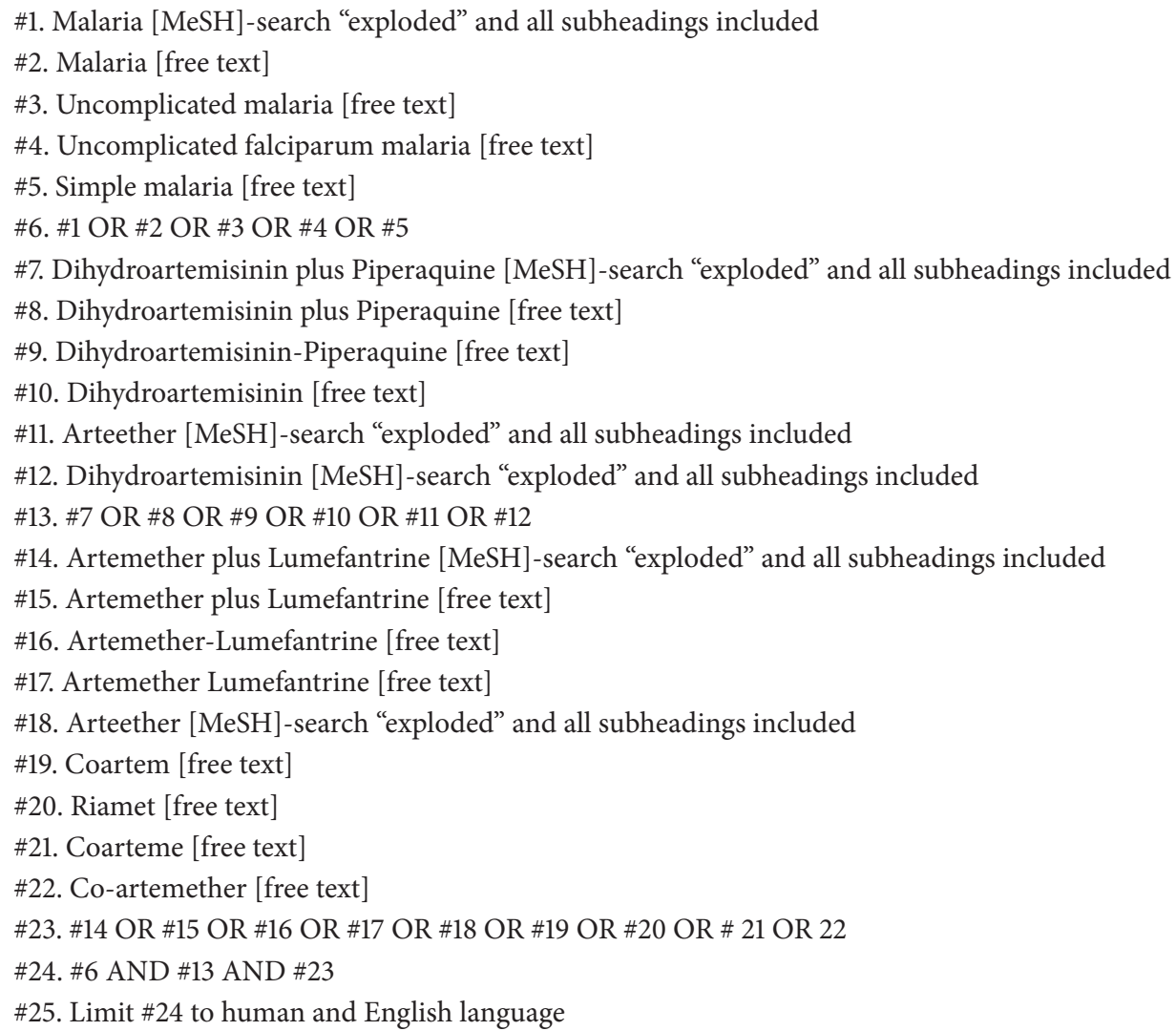

and Global Health, using the search strategy presented in Table 2. The final database search for the review was conducted in the selected databases on June 2, 2013, as follows: EMBASE: from 1980 to 2013 week 22; MEDLINE: from 1946 to May 2013 week 4; Global Health: from 1973 to 2013 week 21.

The main terms in the review question were structured into the PICO (population, intervention, comparison, and outcome) format and all corresponding synonyms identified. All main terms in the review question were searched under medical subject heading (MeSH terms) and also as free texts. Each MeSH term search was "exploded" and all subheadings were included. All other terms (synonyms of the main terms) were searched as free texts. Search results of terms under the same category were brought together using the Boolean operator "OR," while the Boolean operator "AND" was used finally (once) to bring all "OR" results together. The final search result after use of the Boolean operator "AND" was limited to studies conducted on humans and have been published in English language-see Table 3. Only terms in the population, intervention, and comparison categories were used during the search because the reviewers were of the view that further inclusion of terms in the outcome category in the search might lead to exclusion of some important studies. All search results were reviewed by WA and crosschecked by EP and studies that met the inclusion criteria selected. Due to the limited time available for the review, no trial author was contacted for further clarification on the trials and, as a result, articles with instances of unclear or missing data were excluded. The preferred reporting items for systematic reviews and meta-analysis (PRISMA) flow diagram [21] has been used to summarize study selection process-see Figure 1.

2.4. Assessment of Quality (Risk of Bias) of Included Studies. The methodological quality of the selected studies was assessed using the "Cochrane Collaboration's tool for assessing risk of bias" [22]. The assessment tool covers six domains for assessing internal validity of studies. These domains include sequence generation, allocation concealment, blinding of participants or outcome assessors, incomplete outcome data, selective outcome reporting, and other sources of bias [22].

2.5. Data Extraction and Analysis. All data were extracted as binary data in the form of number of participants who experienced the event of interest and total number of participants in each study group. The outcomes of interest included recurrent new falciparum infections (RNIs) and total treatment failure (TTF) reported by day 28 and 42. Data on new infection and treatment failure were extracted using the differentiated PCR results recorded in the studies. Data extraction was done by author WA and figures were crosschecked by author EP for accuracy. Instances of disagreement on the accuracy of the extracted figures were resolved by 


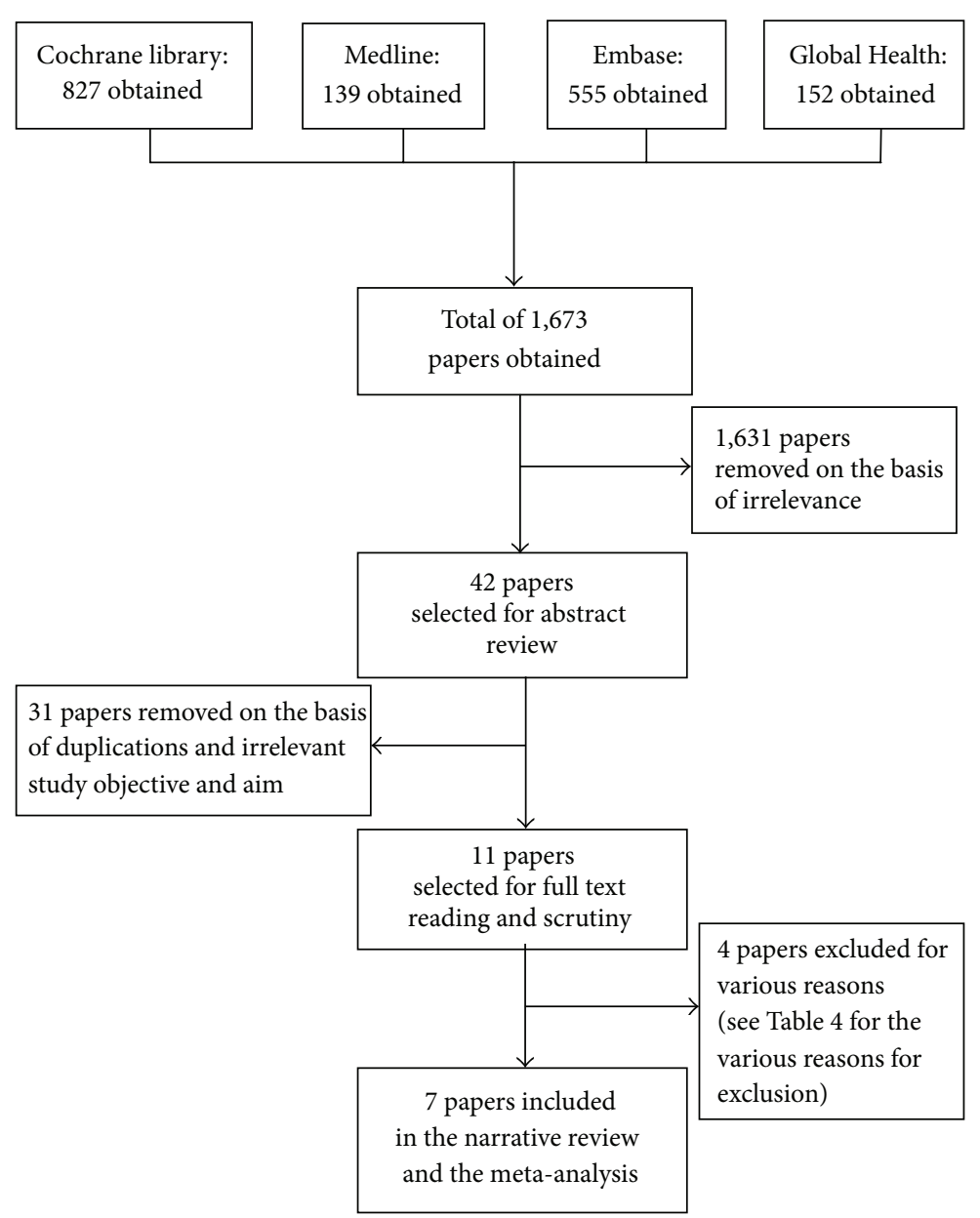

FIGURE 1: The preferred reporting items for systematic reviews and meta-analysis (PRISMA) flow diagram showing database search results and selection stages.

extensive discussions and explanations and then agreement is finally reached on which figure is accurate.

Data analysis was done using the Comprehensive MetaAnalysis programme (CMAP) version 2.0 [23]. Effect sizes were calculated in risk ratio (RR) at $95 \%$ confidence interval (CI). Results of DP group relative to $\mathrm{AL}$ group were regarded as statistically significant if the 95\% CI did not include number of no effect, which is 1 . Absolute relative difference (ARD) and number needed to treat (NNT) were calculated [24]. The grading of recommendations assessment, development, and evaluation (GRADE) system (Table 9) was used to assess level of evidence quality $[25,26]$. The metaanalyses were done in the random effects model. This model operates on the premise that each trial included in the analysis has estimated an effect size peculiar to its study population and that any difference in effect estimation across the studies is due to both random error and heterogeneity [27]. Statistical heterogeneity was assessed to determine $I$ squared $\left(I^{2}\right)$, the $Q$-value, and the accompanying $P$ values [27, 28]. The $I^{2}$ values were interpreted as follows: $I^{2}$ values less than $50 \%$ were regarded as low, values $\geq 50 \%$ were regarded as moderate, and an $I^{2}$ above $75 \%$ was interpreted as high or substantial heterogeneity $[24,28]$. The level of statistical significance for heterogeneity $P$ value was set at $10 \%$ [28].

\section{Search Result}

A total of 1,673 records were retrieved from all the database searches combined and 1,631 records (97.5\%) were excluded initially because they have irrelevant study titles. Abstract of the remaining 42 publications (2.5\%) were read, after which 11 $(26.2 \%)$ were further selected and subjected to thorough full text reading and scrutiny. Seven studies [29-35] were finally selected for inclusion in the review.

The remaining four $[15,36-38]$ were excluded for various reasons (see Table 3 for reasons for exclusion). Table 4 contains general description of selected studies.

\subsection{Risk of Bias Assessment Results of Selected Studies}

3.1.1. Adequate Sequence Generation and Allocation Concealment. Sequence generation was done adequately in all the studies and was judged to pose a low risk of bias. Four of the trials used computer generated random list done by an off-site 
TABLE 3: Table of excluded studies and reasons for exclusion.

\begin{tabular}{|c|c|c|c|}
\hline Study name & Design, country & Sample size & Reasons for exclusion \\
\hline Nambozi et al., 2011 [36] & RCT, Zambia & 304 & $\begin{array}{l}\text { The study has been reported as part of the larger } \\
\text { multicentric study of Bassat et al., 2009, already } \\
\text { included in the review }\end{array}$ \\
\hline Arinaitwe et al., 2009 [15] & RCT, Uganda & 351 & $\begin{array}{l}\text { Some of the study participants were infected with other } \\
\text { species of Plasmodium. The reviewer was only } \\
\text { interested in primary studies in which only } P \text {. } \\
\text { falciparum infections were treated. }\end{array}$ \\
\hline Verret et al., 2011 [37] & RCT, Uganda & 292 & $\begin{array}{l}\text { This study is a subanalysis of the main study of } \\
\text { Arinaitwe et al., 2009, which was also excluded from } \\
\text { the review with reasons as the above. }\end{array}$ \\
\hline Katrak et al., 2009 [38] & RCT, Uganda & 246 & $\begin{array}{l}\text { There was no data on treatment failure; only adverse } \\
\text { events were presented. The main aim of the study was } \\
\text { to investigate safety of study drugs among HIV-infected } \\
\text { and HIV-uninfected children, which is not relevant for } \\
\text { this review. }\end{array}$ \\
\hline
\end{tabular}

investigator. One trial [29] reported use of block randomisation while the remaining two $[32,34]$ used stratified random lists generated by off-site investigators (Figure 2). Five trials $[29,30,32,33,35]$ used adequate allocation concealment methods and were judged to be at low risk for selection bias because the researchers used sequentially numbered, sealed opaque envelops to obscure treatment group before allocation. The concealment process was judged to pose an unclear risk of bias in only two of the studies [31,34] for lack of clear information.

3.1.2. Blinding. Blinding was judged to be adequate (low risk of bias) in six studies [30-35] because all laboratory personnel and trial investigators involved in assessing outcome measures were blinded to the treatment allocation of the study participants. This was deemed to pose low risk of bias to parasitological outcome measures for treatment failure and rate of new infections. One study [29] did not report on blinding and was judged to pose high risk of measurement and performance bias. There was no blinding for participants and nurses in four studies and this was considered to pose rather high risk of bias to the outcome measures of adverse clinical events (side effects of the drugs) which were not the focus of this review.

3.1.3. Inclusion of All Participants in the Final Analysis. All the trials selected addressed incomplete outcome data and were rated to be of low risk for attrition bias. More than $90 \%$ of randomised participants were included in final analysis in all the trials and this was deemed adequate. The highest attrition rate was $7.6 \%$.

3.1.4. Other Sources of Bias. The reviewer identified no other important source of bias.

\section{Findings}

4.1. Total Treatment Failure (TTF) at Day 28. Result on total treatment failure (TTF) due to recrudescence was obtained from six studies and involved a total of 3,172 patients. Of this, 1,861 participants received DP, out of which 107 (5.7\%) experienced treatment failure at day 28. On the other hand, 1,311 received AL, of which 80 (6.1\%) experienced treatment failure. The pooled RR yielded $0.453,95 \% \mathrm{CI}$ : [0.203 to 1.012 , $P=0.05]$. This implies that there was an average of $55 \%$ reduction in risk for TTF at day 28 in favour of DP treatment; largest plausible reduction possible was $80 \%$; however, the upper boundary of the $95 \%$ CI includes the number of no effect (1) and a risk for harm of $1.2 \%$.

Extent of heterogeneity was $47 \%\left(I^{2}=47, P=0.09\right.$, $\mathrm{Q}$-value $=9.5, \mathrm{df}=5)$ and this level of heterogeneity was considered to be low [28] - see Figure 3. The pooled ARD was $0.016,95 \%$ CI $[0.030-0.002, P=0.02]$, which means that for every 63 patients treated with DP, one case of treatment failure was prevented, which would have occurred if such patients had received AL treatment.

4.2. Total Treatment Failure (TTF) at Day 42. Data on TTF at day 42 was extracted from four studies involving 2, 662 participants, out of which treatment failure was reported in 274 participants representing $10.3 \%$. A total of 1,598 participants were those treated with DP and 161 of them (10.1\%) experienced treatment failure. Those who received AL treatment were 1,064 participants out of which 113(10.6\%) experienced failure, an indication that DP was associated with a marginal reduction in treatment failure compared to AL. The pooled estimate for the RR was 0.560 with $95 \%$ CI of [0.275 to $1.140, P=0.1]$. This implies that there was an average reduction in risk of treatment failure of $44 \%$ in favour of DP treatment compared to AL, with the highest plausible reduction in risk of up to $73 \%$. However, the upper boundary of the 95\% CI includes number of no effect (1) and includes $14 \%$ harm of failure. Test for heterogeneity in random effect model shows high statistical heterogeneity of $71 \%$ across the studies $\left(Q=10\right.$, df $\left.(Q)=3, I^{2}=71 \%, P=0.02\right)$ - see Figure 4 .

4.3. Recurrent New Infections (RNIs) Reported at Day 28. Results from four studies involving a total of 2,340 patients 


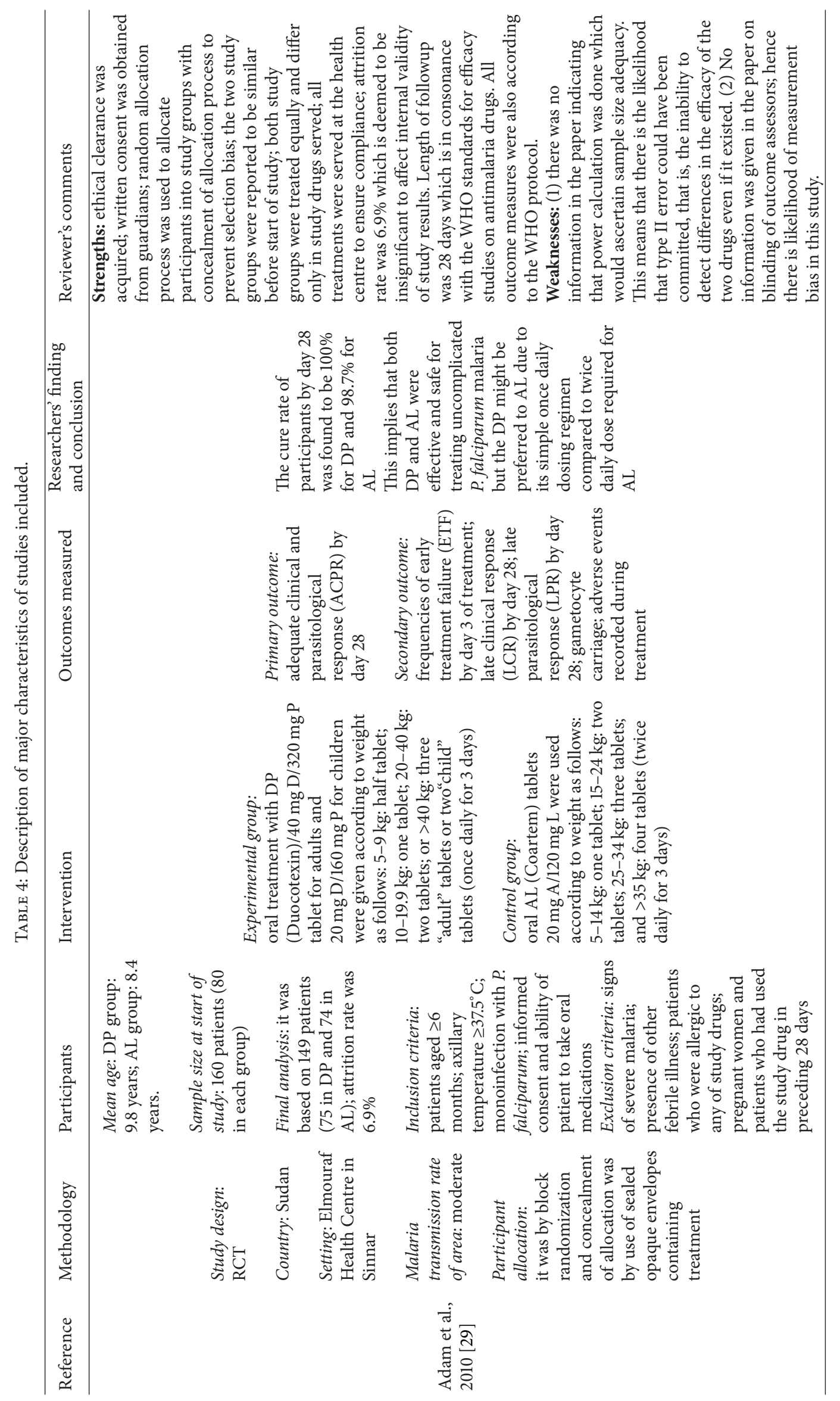




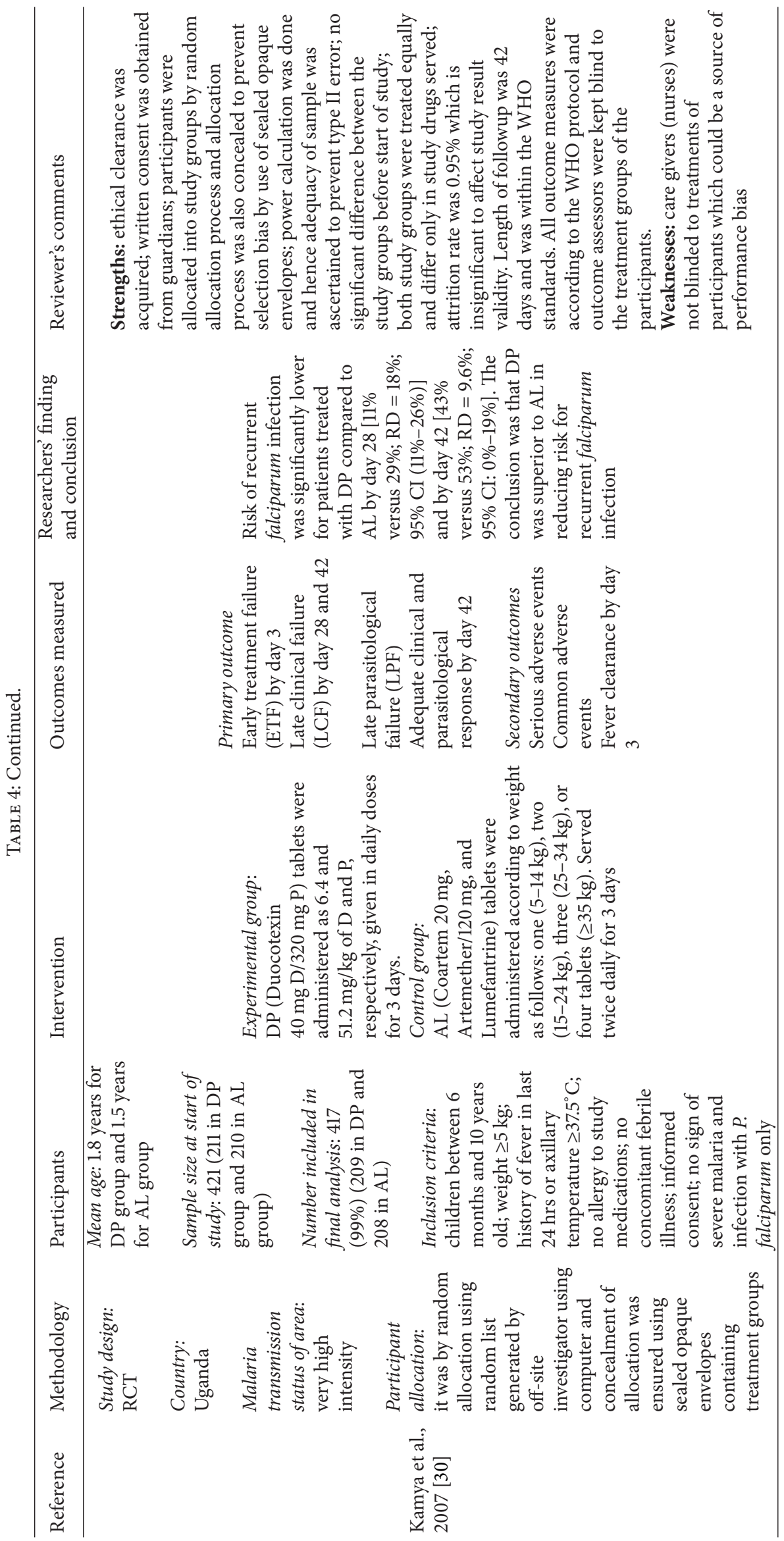




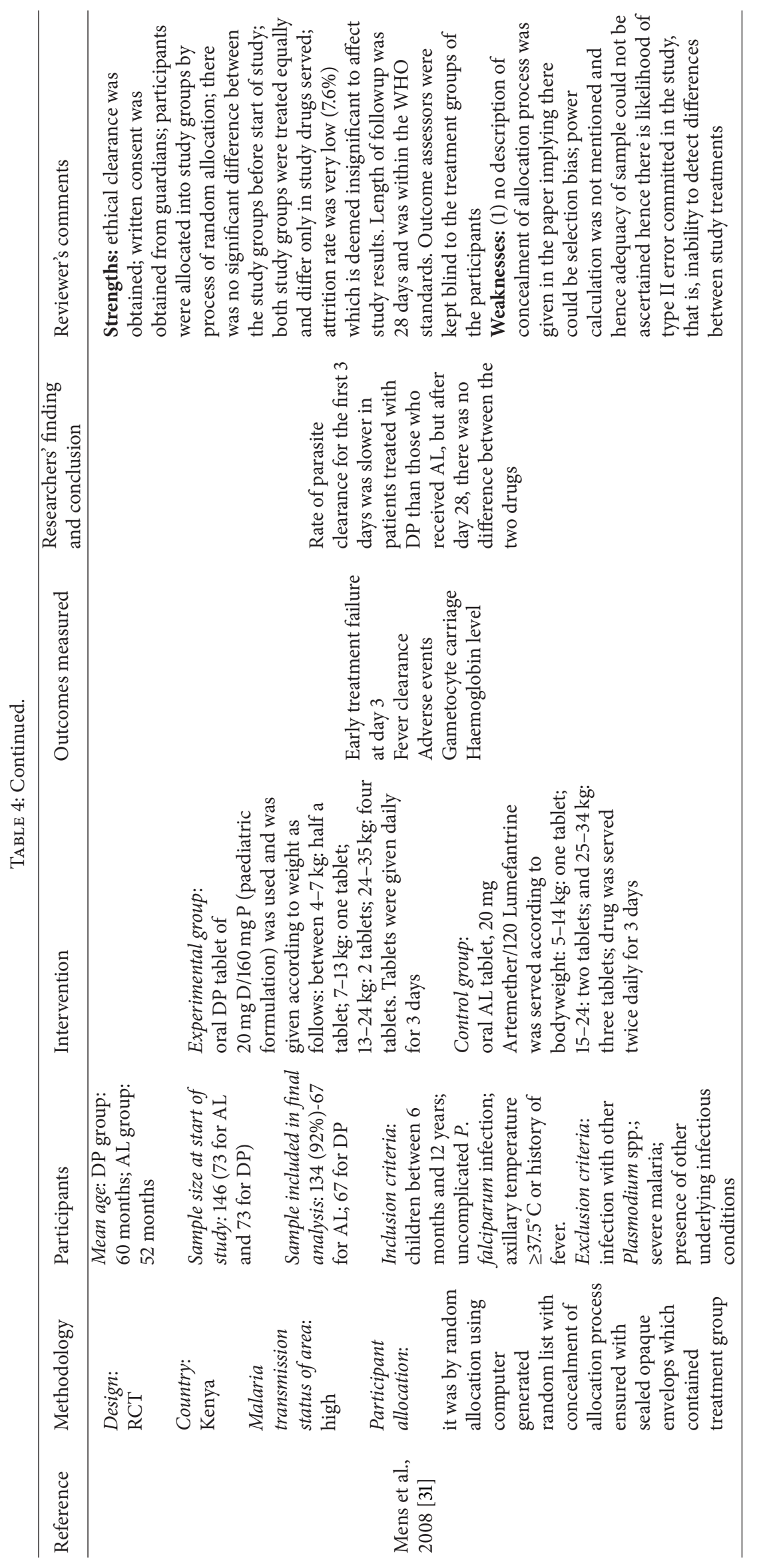




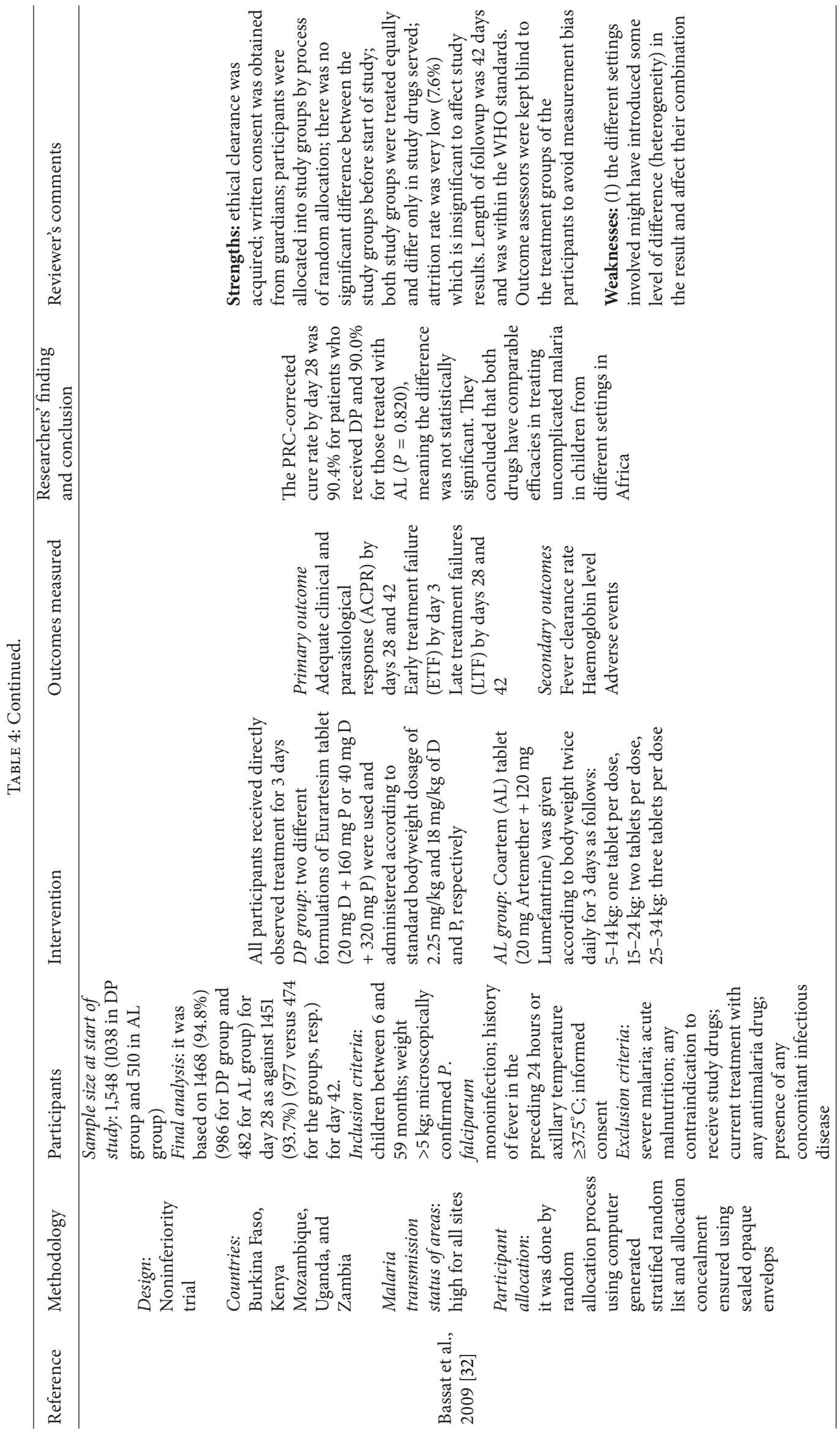




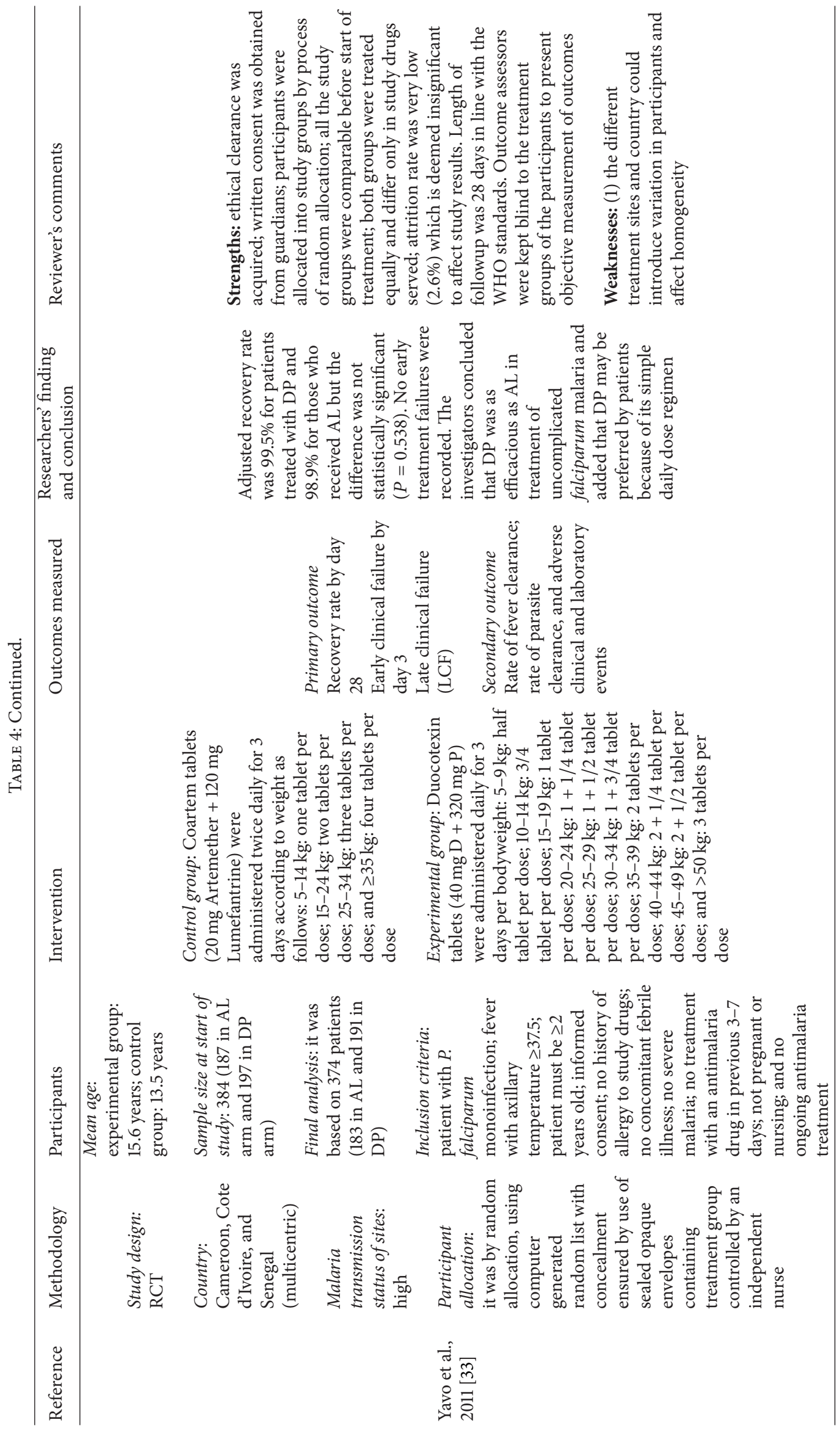



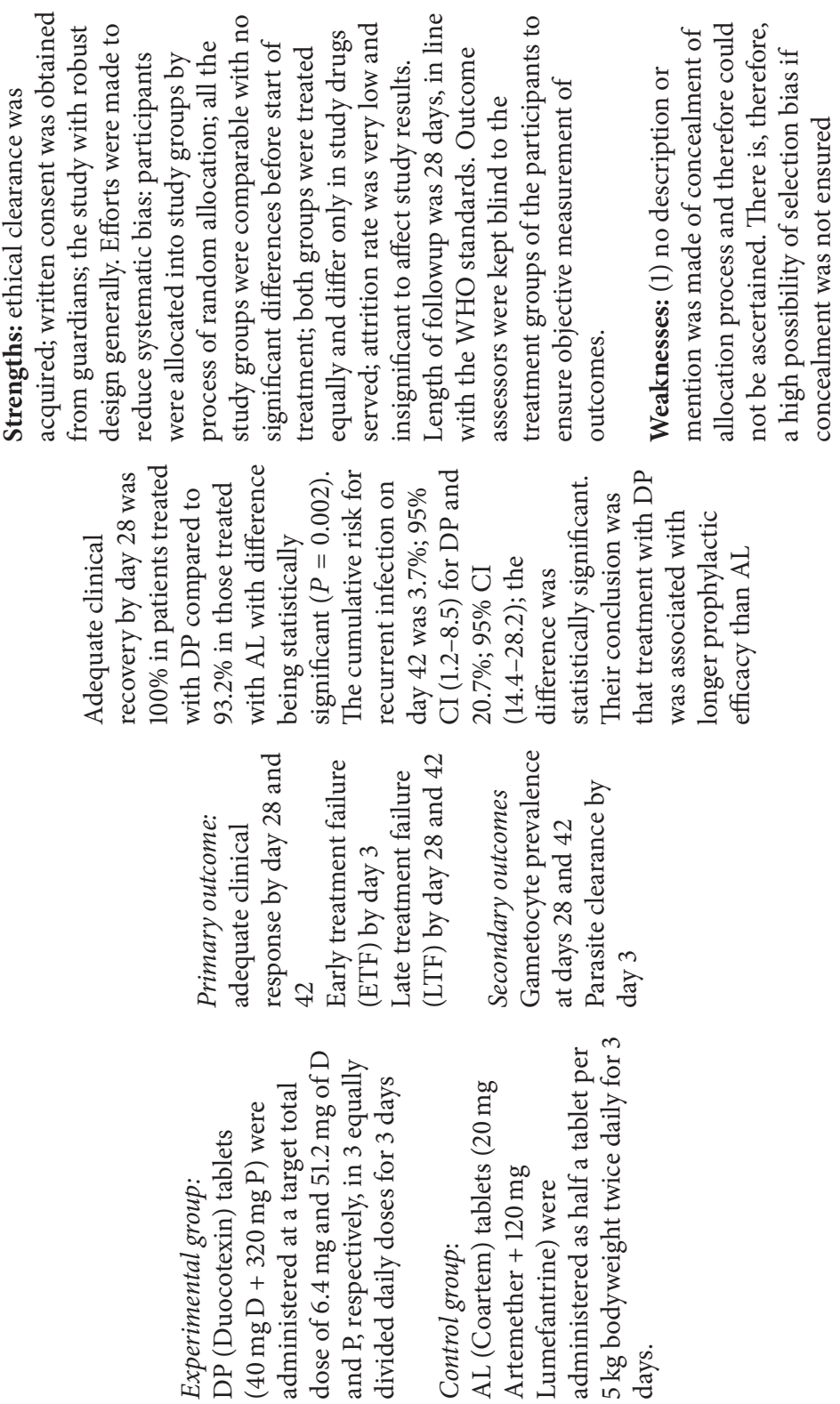

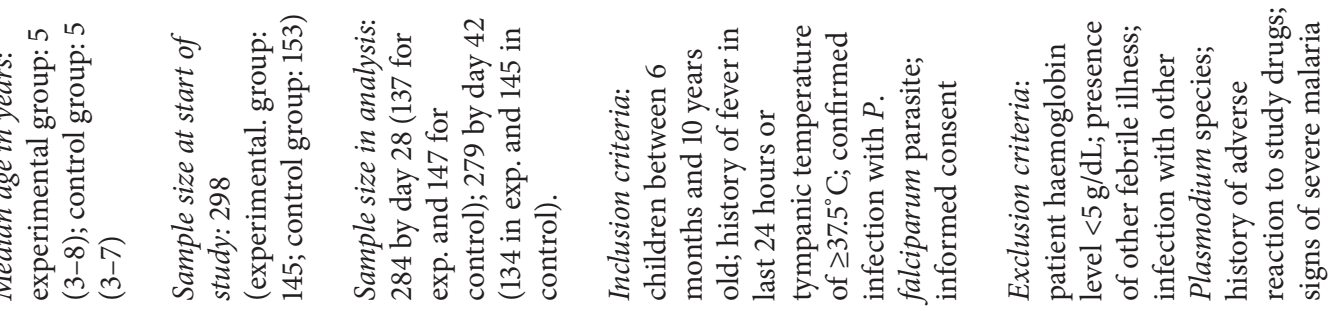

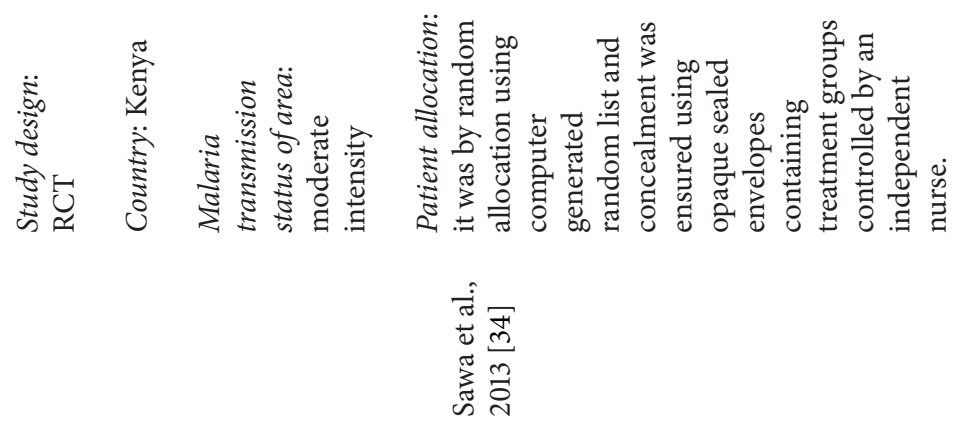




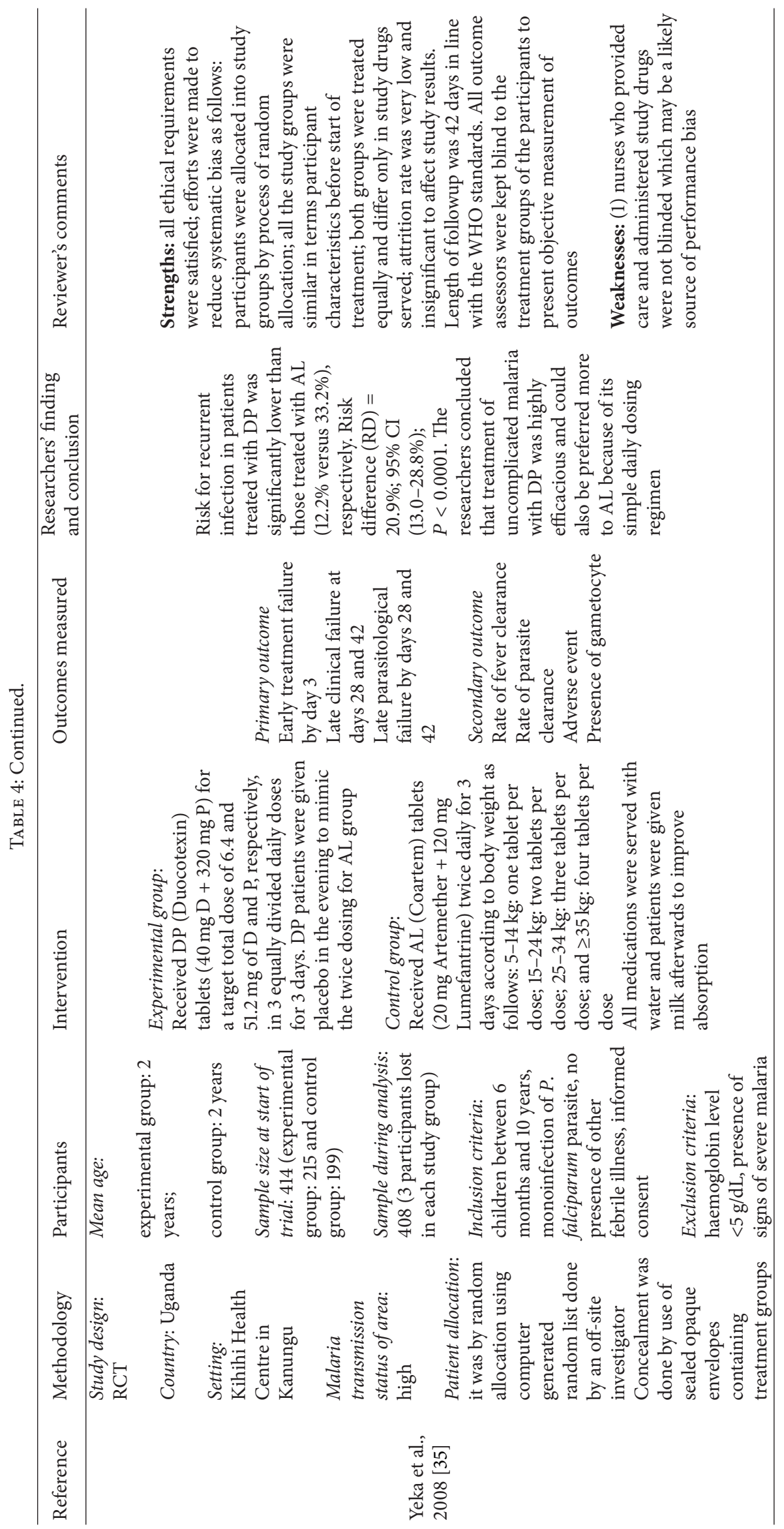


TABLE 5: Findings on total treatment failure (TTF), PCR-corrected by day 28.

\begin{tabular}{|c|c|c|c|c|c|}
\hline Study name & $\begin{array}{l}\text { Study groups with } \\
\text { number of failures }\end{array}$ & Risk $(R)$ & $\begin{array}{c}\text { Risk ratio (RR) } \\
(95 \% \mathrm{CI})\end{array}$ & $P$ value & Interpretation for $\mathrm{RR}$ values \\
\hline $\begin{array}{l}\text { Bassat et al., } \\
2009 \text { [32] }\end{array}$ & $\begin{array}{l}\mathrm{DP}(N / N): 100 / 1038 \\
\quad \operatorname{AL}(n / N): 51 / 510\end{array}$ & $\begin{array}{r}0.096 \\
0.010\end{array}$ & $\begin{array}{c}0.963 \\
(0.699-1.327)\end{array}$ & 0.819 & $\begin{array}{l}\text { This means there is } 3.7 \% \text { reduction in risk of } \\
\text { failure in favour of DP treatment but the result is } \\
\text { not statistically significant. The highest possible } \\
\text { reduction in risk was } 30.1 \% \text {, favouring DP. }\end{array}$ \\
\hline $\begin{array}{l}\text { Yavo et al., } \\
2011[33]\end{array}$ & $\begin{array}{l}\operatorname{DP}(n / N): 1 / 191 \\
\operatorname{AL}(n / N): 2 / 183\end{array}$ & $\begin{array}{l}0.005 \\
0.011\end{array}$ & $\begin{array}{c}0.479 \\
(0.044-5.238)\end{array}$ & 0.546 & $\begin{array}{l}\text { Treatment with DP had contributed to a point } \\
\text { estimate of } 52.1 \% \text { reduction in treatment failure, } \\
\text { with highest possible reduction of } 95.6 \% \text { but the } \\
\text { result is not statistically significant. }\end{array}$ \\
\hline $\begin{array}{l}\text { Kamya et al., } \\
2007[30]\end{array}$ & $\begin{array}{c}\operatorname{DP}(n / N): 4 / 211 \\
\operatorname{AL}(n / N): 18 / 210\end{array}$ & $\begin{array}{l}0.019 \\
0.087\end{array}$ & $\begin{array}{c}0.220 \\
(0.076-0.639)\end{array}$ & 0.005 & $\begin{array}{l}\text { This result shows that DP treatment was } \\
\text { associated with a point estimate reduction of } 78 \% \\
\text { in treatment failure, with lowest and highest of the } \\
\text { estimates being } 36.1 \% \text { and } 92.4 \% \text {, respectively, and } \\
\text { is statistically significant. }\end{array}$ \\
\hline $\begin{array}{l}\text { Sawa et al., } \\
2013 \text { [34] }\end{array}$ & $\begin{array}{l}\mathrm{DP}(n / N): 0 / 137 \\
\operatorname{AL}(n / N): 2 / 147\end{array}$ & $\begin{array}{l}0.000 \\
0.014\end{array}$ & $\begin{array}{c}0.214 \\
(0.010-4.428)\end{array}$ & 0.319 & $\begin{array}{l}\text { DP treatment had contributed to } 78.6 \% \text { reduction } \\
\text { in treatment failure but it is not statistically } \\
\text { significant. The largest plausible reduction would } \\
\text { be } 99 \% \text {. }\end{array}$ \\
\hline $\begin{array}{l}\text { Adam et al., } \\
2010 \text { [29] }\end{array}$ & $\begin{array}{l}\mathrm{DP}(n / N): 0 / 75 \\
\operatorname{AL}(n / N): 1 / 74\end{array}$ & $\begin{array}{l}0.000 \\
0.014\end{array}$ & $\begin{array}{c}0.329 \\
(0.014-7.947)\end{array}$ & 0.494 & $\begin{array}{l}\text { Result shows a statistically insignificant difference } \\
\text { between DP and AL treatment in preventing } \\
\text { treatment failure but indicates that there was a } \\
67.1 \% \text { risk of failure reduction in favour of DP } \\
\text { treatment }(1>\mathrm{RR} \text {, } \\
1-\mathrm{RR}=1-0.329=0.671 \times 100=67.1 \%) \text {. }\end{array}$ \\
\hline $\begin{array}{l}\text { Yeka et al., } \\
2008 \text { [35] }\end{array}$ & $\begin{array}{l}\mathrm{DP}(n / N): 2 / 211 \\
\mathrm{AL}(n / N): 6 / 190\end{array}$ & $\begin{array}{l}0.009 \\
0.032\end{array}$ & $\begin{array}{c}0.300 \\
(0.061-1.469)\end{array}$ & 0.138 & $\begin{array}{l}\text { Result is not significant statistically but there was } \\
\text { a reduction in failure in favour of DP treatment of } \\
70 \% \text {. The highest reduction possible was } 93.9 \% \text { in } \\
\text { favour of DP treatment of falciparum malaria. }\end{array}$ \\
\hline
\end{tabular}

TABLE 6: Findings on total treatment failure (TTF), PCR-corrected by day 42 .

\begin{tabular}{|c|c|c|c|c|c|}
\hline Study name & $\begin{array}{l}\text { Study groups with } \\
\text { number of failures }\end{array}$ & Risk $(R)$ & $\begin{array}{l}\text { Risk ratio (RR) } \\
\quad(95 \% \mathrm{CI})\end{array}$ & $P$ value & Interpretation of RR values \\
\hline $\begin{array}{l}\text { Bassat et al., } \\
2009 \text { [32] }\end{array}$ & $\begin{array}{l}\mathrm{DP}(N / N): 143 / 1038 \\
\operatorname{AL}(n / N): 68 / 510\end{array}$ & $\begin{array}{l}0.138 \\
0.133\end{array}$ & $\begin{array}{c}1.033 \\
(0.790-1.352)\end{array}$ & 0.811 & $\begin{array}{l}\text { There was a marginal increase in treatment failure } \\
\text { of 3.3\% associated with DP treatment but it is not } \\
\text { statistically significant. }\end{array}$ \\
\hline $\begin{array}{l}\text { Kamya et al., } \\
2007[30]\end{array}$ & $\begin{array}{l}\mathrm{DP}(n / N): 13 / 211 \\
\operatorname{AL}(n / N): 28 / 210\end{array}$ & $\begin{array}{r}0.062 \\
0.133\end{array}$ & $\begin{array}{c}0.452 \\
(0.245-0.867)\end{array}$ & 0.016 & $\begin{array}{l}\text { This result shows that DP treatment was } \\
\text { associated with a point estimate reduction of } \\
54.8 \% \text { in treatment failure; with lowest and } \\
\text { highest of the estimates being } 13.3 \% \text { and } 75.5 \% \text {, } \\
\text { respectively, and it is statistically significant. }\end{array}$ \\
\hline $\begin{array}{l}\text { Sawa et al., } \\
2013 \text { [34] }\end{array}$ & $\begin{array}{l}\mathrm{DP}(n / N): 0 / 134 \\
\mathrm{AL}(n / N): 4 / 145\end{array}$ & $\begin{array}{l}0.000 \\
0.028\end{array}$ & $\begin{array}{c}0.120 \\
(0.007-2.211)\end{array}$ & 0.154 & $\begin{array}{l}\text { DP treatment had contributed to } 88 \% \text { reduction } \\
\text { in treatment failure but it is not statistically } \\
\text { significant. The largest plausible reduction was } \\
99.3 \% \text {. }\end{array}$ \\
\hline $\begin{array}{l}\text { Yeka et al., } \\
2008 \text { [35] }\end{array}$ & $\begin{array}{l}\mathrm{DP}(n / N): 5 / 215 \\
\mathrm{AL}(n / N): 13 / 199\end{array}$ & $\begin{array}{l}0.023 \\
0.065\end{array}$ & $\begin{array}{c}0.356 \\
(0.129-0.981)\end{array}$ & 0.045 & $\begin{array}{l}\text { This result is statistically significant. There was a } \\
\text { reduction in failure in favour of DP treatment of } \\
64.4 \% \text {. The highest possible reduction was } 87 \% \\
\text { and the lowest was } 2 \% \text { in favour of DP treatment } \\
\text { of falciparum malaria. }\end{array}$ \\
\hline
\end{tabular}

showed that 104 of the patients (representing 4.4\%) acquired new falciparum infections within the 28 day period after treatment. Out of the total number, 1,433 participants received DP, of which 28 patients representing $2 \%$ had new infections. In the AL group, 907 patients received the treatment and $76(8 \%)$ acquired new infections - an indication that rate of new falciparum infection was higher among those treated with AL than those treated with DP. Pooled RR was 0.207, 95\% CI [0.136 to $0.315, P<0.001]$. This indicates that risk associated with a patient getting new infections at day 28 was significantly reduced averagely by $79 \%$ in favour of DP treatment. The lowest plausible reduction was $69 \%$ 
TABLE 7: Findings on new falciparum infections detected by day 28 .

\begin{tabular}{|c|c|c|c|c|c|}
\hline Study name & $\begin{array}{l}\text { Study groups with } \\
\text { number of new } \\
\text { infections }\end{array}$ & Risk $(R)$ & $\begin{array}{l}\text { Risk ratio (RR) } \\
\quad(95 \% \mathrm{CI})\end{array}$ & $P$ value & Interpretation for the $R R$ values \\
\hline $\begin{array}{l}\text { Sawa et al., } \\
2013 \text { [34] }\end{array}$ & $\begin{array}{l}\mathrm{DP}(n / N): 0 / 137 \\
\operatorname{AL}(n / N): 8 / 147\end{array}$ & $\begin{array}{l}0.00 \\
0.054\end{array}$ & $\begin{array}{c}0.063 \\
(0.004-1.083)\end{array}$ & 0.057 & $\begin{array}{l}\text { There has been } 37 \% \text { reduction in new infections } \\
\text { associated with DP treatment but reduction is not } \\
\text { statistically significant. }\end{array}$ \\
\hline $\begin{array}{l}\text { Yavo et al., } \\
2011[33]\end{array}$ & $\begin{array}{l}\mathrm{DP}(n / N): 1 / 191 \\
\operatorname{AL}(n / N): 3 / 183\end{array}$ & $\begin{array}{r}0.005 \\
0.016\end{array}$ & $\begin{array}{c}0.319 \\
(0.034-3.042)\end{array}$ & 0.321 & $\begin{array}{l}\text { There was a } 68 \% \text { reduction in new infections in } \\
\text { favour of DP treatment but result not statistically } \\
\text { significant. }\end{array}$ \\
\hline $\begin{array}{l}\text { Bassat et al., } \\
2009 \text { [32] }\end{array}$ & $\begin{array}{l}\mathrm{DP}(n / N): 27 / 1038 \\
\mathrm{AL}(n / N): 64 / 510\end{array}$ & $\begin{array}{r}0.026 \\
0.125\end{array}$ & $\begin{array}{c}0.207 \\
(0.134-0.321)\end{array}$ & $<0.001$ & $\begin{array}{l}\text { This result shows } 79 \% \text { reduction in incidence of } \\
\text { new falciparum infections in favour of DP } \\
\text { treatment and the reduction is statistically } \\
\text { significant. The lowest plausible reduction is } \\
67.9 \% \text { while the highest is } 86.6 \% \text { as defined by the } \\
95 \% \text { CI of the RR. }\end{array}$ \\
\hline $\begin{array}{l}\text { Mens et al., } \\
2008 \text { [31] }\end{array}$ & $\begin{array}{l}\mathrm{DP}(n / N): 0 / 67 \\
\operatorname{AL}(n / N): 1 / 67\end{array}$ & $\begin{array}{r}0.000 \\
0.015\end{array}$ & $\begin{array}{c}0.333 \\
(0.014-8.039)\end{array}$ & 0.499 & $\begin{array}{l}\text { DP treatment was associated with a } 66.7 \% \\
\text { reduction in risk for a patient to acquire new } \\
\text { infections compared to AL. The reduction is not } \\
\text { statistically significant. }\end{array}$ \\
\hline
\end{tabular}

TABLE 8: Total new falciparum infections detected by day 42 .

\begin{tabular}{|c|c|c|c|c|c|}
\hline Study name & $\begin{array}{l}\text { Study groups with } \\
\text { number of new } \\
\text { infections }\end{array}$ & Risk $(R)$ & $\begin{array}{l}\text { Risk ratio (RR) } \\
\quad(95 \% \mathrm{CI})\end{array}$ & $P$ value & Interpretation for the RR values \\
\hline $\begin{array}{l}\text { Sawa et al., } \\
2013 \text { [34] }\end{array}$ & $\begin{array}{l}\mathrm{DP}(n / N): 3 / 134 \\
\mathrm{AL}(n / N): 23 / 145\end{array}$ & $\begin{array}{l}0.022 \\
0.159\end{array}$ & $\begin{array}{c}0.141 \\
(0.043-0.459)\end{array}$ & 0.001 & $\begin{array}{l}\text { There has been } 85.9 \% \text { reduction in new infection } \\
\text { associated with DP treatment. Highest plausible } \\
\text { reduction is } 95 \% \text { while lowest is } 54 \% \text { defined by the } \\
95 \% \text { CI. The reduction is statistically significant. }\end{array}$ \\
\hline $\begin{array}{l}\text { Yeka et al., } \\
2008 \text { [35] }\end{array}$ & $\begin{array}{l}\mathrm{DP}(n / N): 16 / 215 \\
\mathrm{AL}(n / N): 30 / 199\end{array}$ & $\begin{array}{r}0.074 \\
0.151\end{array}$ & $\begin{array}{c}0.494 \\
(0.278-0.878)\end{array}$ & 0.016 & $\begin{array}{l}\text { There was } 50.6 \% \text { reduction in risk to acquire new } \\
\text { falciparum infection in favour of DP treatment and the } \\
\text { reduction is statistically significant. }\end{array}$ \\
\hline $\begin{array}{l}\text { Bassat et al., } \\
2009 \text { [32] }\end{array}$ & $\begin{array}{l}\mathrm{DP}(n / N): 122 / 1038 \\
\operatorname{AL}(n / N): 105 / 510\end{array}$ & $\begin{array}{l}0.118 \\
0.206\end{array}$ & $\begin{array}{c}0.571 \\
(0.450-0.725)\end{array}$ & $<0.001$ & $\begin{array}{l}\text { This result shows } 42.9 \% \text { reduction in risk of getting new } \\
\text { infections with falciparum and the reduction was in } \\
\text { favour of DP and is statistically significant. The lowest } \\
\text { plausible reduction is } 27.5 \% \text { while the highest is } 55 \% \text { as } \\
\text { defined by the } 95 \% \text { CI of the RR. }\end{array}$ \\
\hline $\begin{array}{l}\text { Kamya et al., } \\
2007[30]\end{array}$ & $\begin{array}{l}\mathrm{DP}(n / N): 77 / 211 \\
\mathrm{AL}(n / N): 79 / 210\end{array}$ & $\begin{array}{l}0.365 \\
0.376\end{array}$ & $\begin{array}{c}0.970 \\
(0.756-1.244)\end{array}$ & 0.811 & $\begin{array}{l}\text { DP treatment was associated with only } 3 \% \text { risk } \\
\text { reduction for new infection and the reduction is } \\
\text { statistically insignificant. }\end{array}$ \\
\hline
\end{tabular}

and highest was $86 \%$; the difference was statistically significant $(P<0.001)$ - Figure 5 .

4.4. Recurrent New Infections (RNIs) Detected at Day 42. Results extracted from four studies involving a total of 2,662 patients indicated that 455 patients representing $17 \%$ experienced new infections with falciparum parasites. Those treated with DP were 1,598, out of which 218 (14\%) acquired new falciparum infections. On the other hand, a total of 1,064 received AL, of which 237 (22\%) experienced new infections. The pooled RR was $0.557,95 \%$ CI [ 0.342 to 0.908 ]. This means that the risk of a patient acquiring new falciparum infection at 42 day following treatment was averagely reduced by $44 \%$ in favour of DP compared to AL-see Figure 6. The 95\% CI was 0.342 to 0.908 , suggesting that the actual effect could be anywhere between 9 and 66\%; the difference was statistically significant, $P=0.02$. There was a substantial heterogeneity (extent was $83 \%)$ associated with this result $\left(I^{2}=83\right.$, Q-value $=18, \mathrm{df}=3, P<0.001)$.

\section{Discussion}

This review compared two ACTs-DihydroartemisininPiperaquine (DP) and Artemether-Lumefantrine (AL) - to determine which has the greatest effect in reducing recurrent new falciparum infections (RNIs) and treatment failure. The null hypothesis which was tested was that there is no difference between the two drugs in reducing risk of treatment failure and recurrent new falciparum infections at days 28 and 42 . However, the overall evidence gathered suggests that patients who were treated with DP experienced less total 


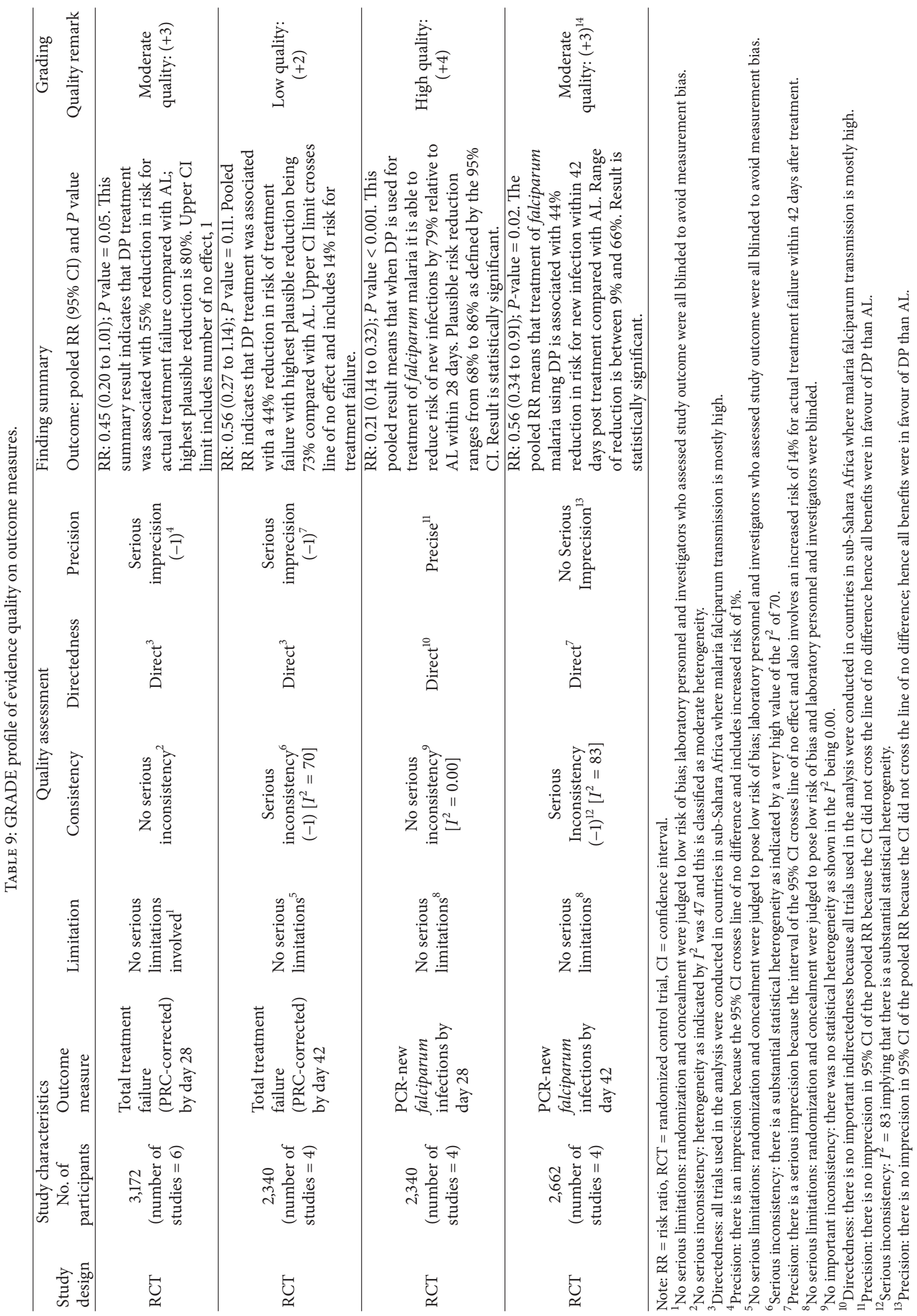




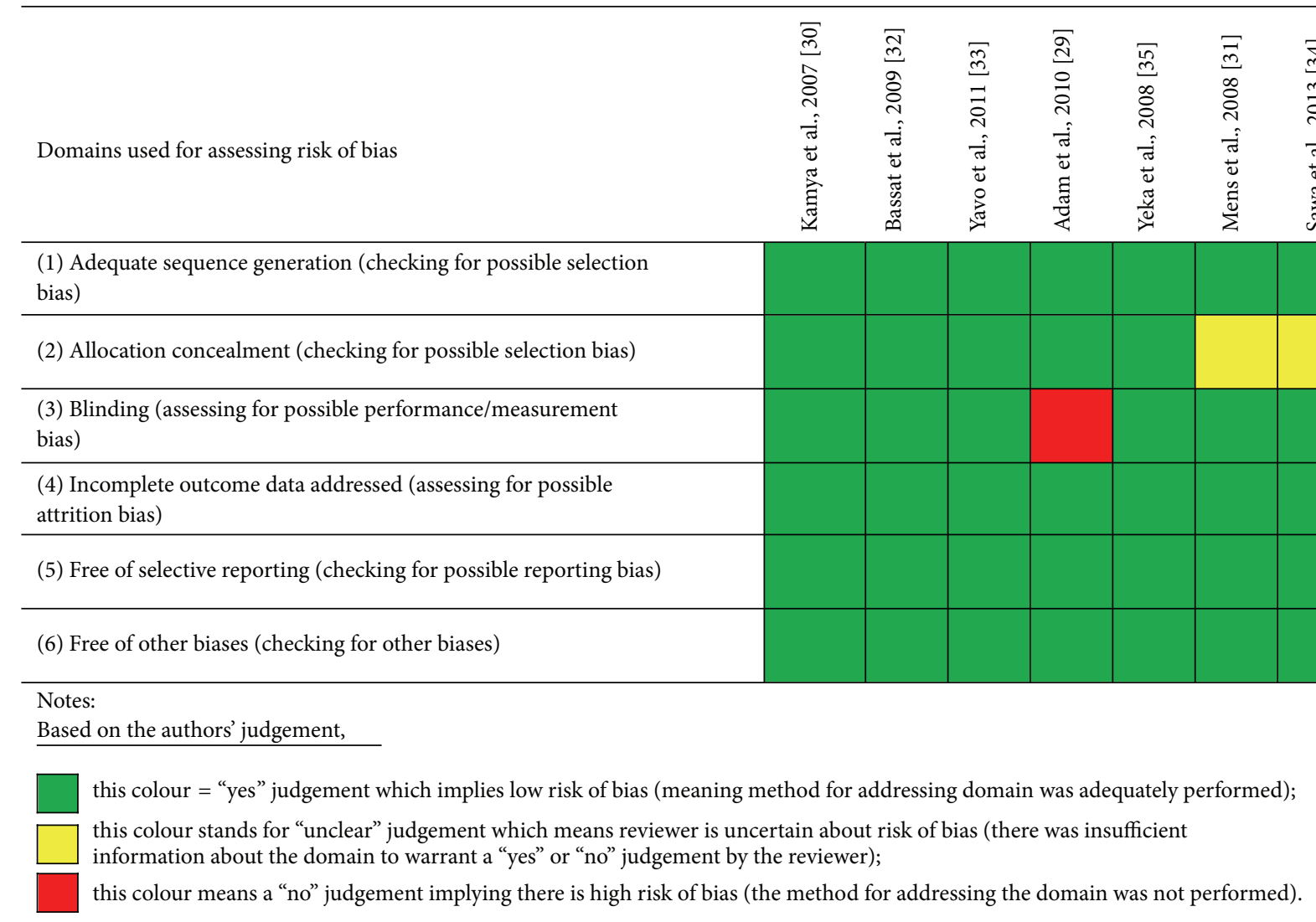

FIGURE 2: Result of risk of bias assessment for included studies.

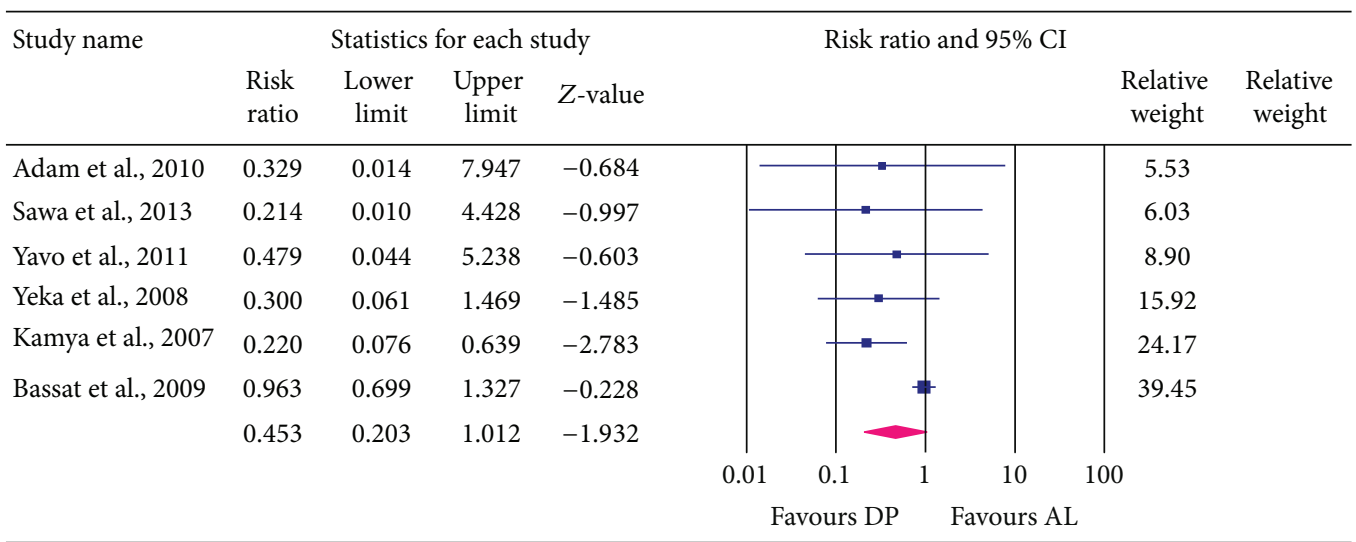

Heterogeneity: $Q$-value $=9.5, \mathrm{df}=5(P=0.09), I^{2}=48$; test of null $(2$-tail $): Z$-value $=-1.93(P=0.05)$

FIGURE 3: Analysis for Dihydroartemisinin-Piperaquine versus Artemether-Lumefantrine for outcome of total treatment failure (PCRcorrected) at day 28.

treatment failure (TTF) and less recurrent new falciparum infections (RNIs) than those who received AL.

Majority of studies included in this review were conducted in East Africa and only few were carried out in West Africa and therefore findings and conclusion are more applicable to countries in the East Africa region. The evidence synthesized indicates that both DP and AL are effective in preventing treatment failure at days 28 and 42 after treatment. However, DP reduced treatment failure higher than AL at
28 and 42 days but the difference in magnitude of failure reduction between the two drugs is clinically marginal and not statistically significant. This finding concurs with that of earlier review conducted on studies done in Asia, America, and Africa [18], in which DP was found to be associated with an appreciable efficacy of cure rate compared to non-ACT and other ACT drugs. The average percentage of risk reduction in favour of DP compared to AL in this review decreased from $55 \%$ at day 28 to $44 \%$ at day 42 . This confirms the assertion 


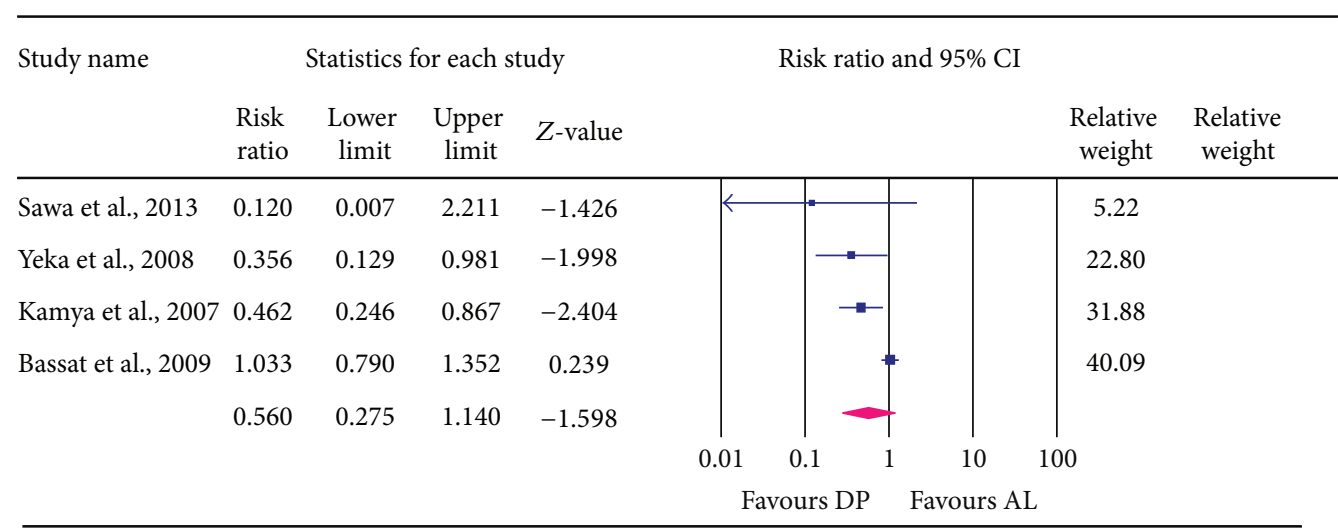

Heterogeneity: $Q$-value $=10, \mathrm{df}=3(P=0.02), I^{2}=71$; test of null $(2$-tail $): Z$-value $=-1.59(P=0.1)$.

FIGURE 4: Analysis for Dihydroartemisinin-Piperaquine versus Artemether-Lumefantrine for outcome of total treatment failure (PCRcorrected) at day 42 .

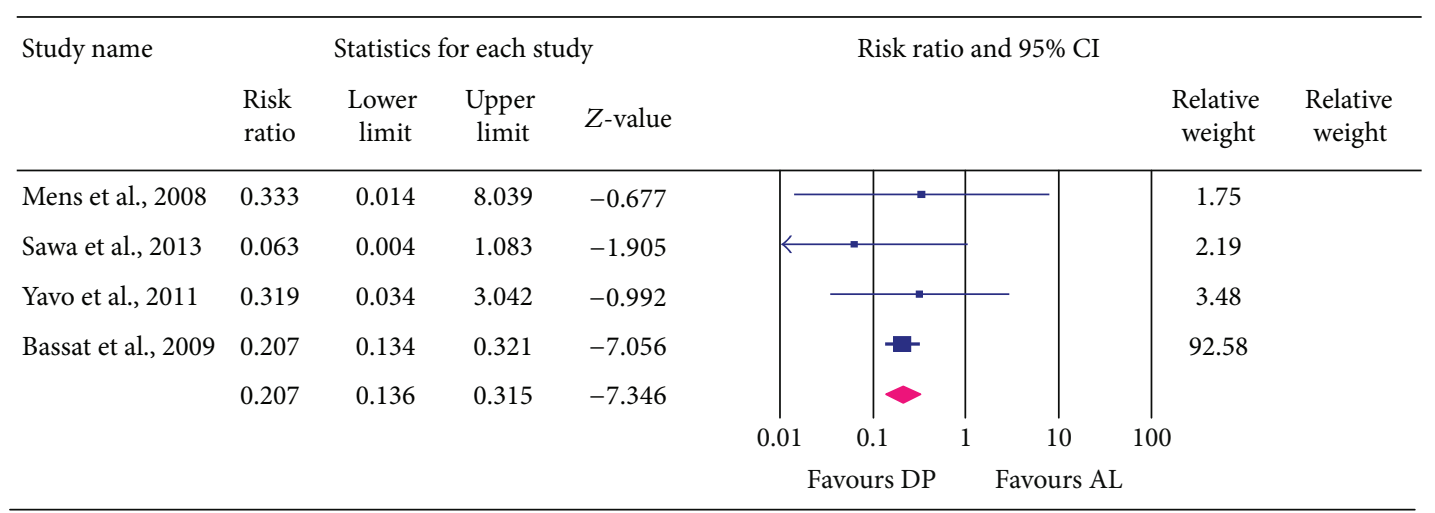

Heterogeneity: $Q$-value $=0.9, \mathrm{df}=3(P=0.8), I^{2}=0.00$; test of null $(2$-tail $): Z$-value $=-7.34(P=0.001)$.

FIGURE 5: Analysis for Dihydroartemisinin-Piperaquine versus Artemether-Lumefantrine for outcome of recurrent new falciparum infection at day 28.

by Yeka and colleagues that as length of followup increases, difference between DP and AL in their ability to prevent treatment failure in high endemic areas becomes insignificant [35]. This observation is attributed to the overwhelming rate of new infections in such areas which may have outweighed the efficacy of Piperaquine coupled with the decreasing concentration of Piperaquine in the blood stream over time.

It has been speculated that DP could offer a greater posttreatment prophylaxis (PTP) than other ACTs due to its longer half-life by which it could exert longer efficacy against newly infecting parasites and reduce risk for development of both clinical malaria and resistance parasite strains [14]. However, the extent to which DP could offer prophylaxis (PTP) by preventing clinical malaria due to new infections has not been clearly specified compared to other ACTs such as $\mathrm{AL}$.

Result on prevention of recurrent new falciparum infections (RNIs) in this review demonstrates that DP offered greater and significant PTP for patients against RNI than AL. Average percentage reduction in risk for RNI was up to $79 \%$ at day 28 in favour of DP and up to $44 \%$ at day 42 in favour of DP. There is, however, substantially significant statistical heterogeneity (extent was 83\%) associated with pooled result on RNI at day 42 in this review. The possible source of this heterogeneity is attributed to the variability in malaria infection transmission rate of the various study sites; some of the studies were conducted in settings where rate of malaria transmission intensity was very high while other studies were conducted in areas of relatively low malaria transmission intensity. Thus, study settings with very high transmission intensity are likely to be associated with higher rates of Anopheles mosquito bites which will result in recurrent new infections more than settings with low transmission intensities. Even though participants were provided with insecticide treated nets, it cannot be ascertained whether patients actually slept in the nets to prevent mosquito bites after treatment and this could also affect the proportion of patient who experienced recurrent new infections.

The superiority of DP in offering this higher level of posttreatment prophylaxis (PTP) is attributable to the longer half-life of Piperaquine (which is $\sim 5$ weeks) compared to the shorter half-life (of about 4 to 5 days) of Lumefantrine in AL [14]. The higher PTP of DP will be of significant importance for areas of higher malaria transmission intensities more 


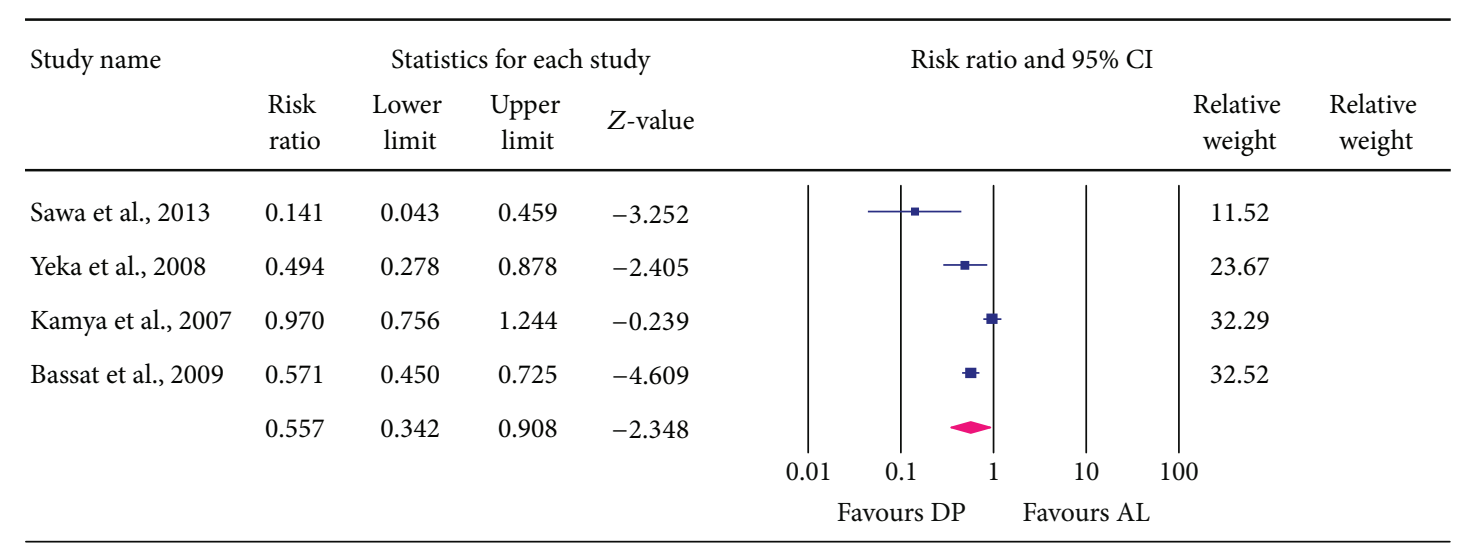

Heterogeneity: $Q$-value $=18, \mathrm{df}=3(P<0.001), I^{2}=83$; test of null $(2$-tail $): Z$-value $=-2.35(P=0.02)$.

Figure 6: Analysis for Dihydroartemisinin-Piperaquine versus Artemether-Lumefantrine for outcome of recurrent new falciparum infection at day 42 .

than for areas of low transmission intensities which are associated with lower frequency of acquiring malaria due to new infections. However, in spite of the benefit of higher PTP of DP it must also be pointed out that the longer half-life of Piperaquine is likely to pose high risk for faster development of drug resistant strains of the falciparum parasites to DP [14]. This is thought to be possible because the new infecting parasites will be exposed to subtherapeutic (low) concentrations of Piperaquine over time. This low concentration will not be able to eliminate the parasites completely and will provide an opportunity for development of resistant strains. Therefore, any attempt to promote more utilisation of DP for the benefit associated with its higher PTP must be weighed against the possible risk for development of resistant strains because of potential public health dangers associated with drug resistant parasites. Notwithstanding, the risk for development of drug resistant parasites could be minimized if more than one ACT drug is used as a first-line drug for treatment of uncomplicated malaria in a particular area [15].

The use of more than one drug as a first-line ACT may prevent the possibility of the parasites becoming adjusted to one overused-first-line ACT. There is, therefore, the need for encouraging the use of multiple first-line drugs and constant monitoring of efficacy of the ACT drugs to determine development of resistant strains at early stages.

5.1. Clinical and Policy Implications of Findings. Using the GRADE criteria for rating evidence quality [26], the quality of evidence obtained regarding superiority of DP over AL in preventing TTF at day 28 was rated moderate quality while that of day 42 was rated low quality. Evidence obtained on prophylactic superiority of DP over AL in preventing RNI at day 28 was rated high quality while that of day 42 was rated moderate quality. High quality GRADE evidence rating means that the authors are very confident that the true effect lies close to the average estimated while moderate quality rating means that authors' confidence in the estimate is moderate which means that the true effect size is likely to be close to the average estimate, but there is also likelihood that there could be substantial difference [26].
It is worth indicating that treatment failure (TTF) and recurrent new infections (RNIs) are of great importance and concern to patients due to the negative socioeconomic impact of clinical malaria on patients. Malaria imposes high economic burden on patients by preventing them from working when the disease attacks them and this slows work force productivity. Malaria is highly prevalent in sub-Sahara Africa and it is undeniable that patients acquiring frequent recurrent new infections contribute to the high number of cases. Therefore, preventing RNIs means that an appreciable proportion of the population would remain healthier for productive economic activities and this could help reduce the malaria expenditure burden on the healthcare system and on the continent as well as on donor agencies. Considering these reasons above and level of relative reduction in risk for TTF and RNI in favour of DP together with the quality of the evidence obtained, these findings are considered to be of clinical and country malaria policy significance.

5.2. Strengths of the Review. All studies included in the review were RCTs which is appropriate for answering clinical intervention questions. The methodological quality of the selected studies was generally high and had been rated to pose low risk of bias. Meta-analysis was done in random effects model to integrate extracted data for better interpretation and all these are considered as strengths of the review. Data extracted from the various studies were done by AW and cross-checked by EP to ensure accuracy and prevent individual bias.

5.3. Limitations of the Review. There was no attempt to locate studies in the grey literature and other sources apart from those indexed in the four databases searched. Search results were limited to studies published in English language alone and therefore excluded other equally valuable articles which might have been published in other languages such as French. All of these carry a potential risk of selection bias which could undermine the completeness of the review data and weaken findings and conclusion. There are variations associated with 
the studies. Firstly the studies were conducted in different sites that have different malaria transmission intensities. Studies also recruited participants with different age groups. Also, majority of the included studies were conducted in countries in East Africa which weakens generalisation of findings to other parts of sub-Sahara Africa; hence this review result and conclusion are most valid for countries in East Africa. There is high statistical heterogeneity associated with some estimates; hence each pooled effect estimate must be seen as an average representing different estimates which are peculiar to each study population, bearing in mind, however, that effect directions were similar and, in most cases, favoured DP (see forest plots in Figures 3-6).

\section{Conclusion}

This systematic review compared DihydroartemisininPiperaquine (DP) and Artemether-Lumefantrine (AL) and aimed at identifying which one has greater ability to reduce total treatment failure (TTF) and incidence of recurrent new falciparum infections (RNIs) in high transmission areas in sub-Sahara Africa. The results showed that participants treated with DP compared to AL experienced lesser risk for TTF at days 28 and 42 .

On the other hand, DP offers a significant posttreatment prophylaxis against recurrent new falciparum infections superior to that of $\mathrm{AL}$. The average percentage reduction in risk for the incidence of RNI was up to $79 \%$ at day 28 in favour of DP [RR, $0.21 ; 95 \% \mathrm{CI}$ : 0.14 to $0.32, P<$ 0.001 ] and $44 \%$ in favour of DP at day 42 [RR, 0.56; $95 \%$ CI: 0.34 to $0.90 ; P=0.02]$. It is, therefore, concluded that treatment of uncomplicated falciparum malaria using Dihydroartemisinin-Piperaquine (DP) in high transmission areas in sub-Sahara Africa (especially East Africa) could result in an average reduction in risk for recurrent new falciparum infections of up to $79 \%$ and $44 \%$ within 28 and 42 days, respectively, compared to Artemether-Lumefantrine $(\mathrm{AL})$. And this implies that use of DP can help reduce burden of malaria in such areas more than AL. However, both DP and AL have similar effectiveness in preventing treatment failure though DP has marginal benefit over AL.

\section{Recommendation}

It is recommended that the antimalaria drug policy in countries especially in East Africa should be streamlined to include use of Dihydroartemisinin-Piperaquine alongside Artemether-Lumefantrine and other ACTs in countries where it is found to be effective but this must be done bearing in mind the potential risk for development of resistant falciparum strains. More studies should be conducted in other parts of the sub-Sahara Africa such as West Africa to determine stronger evidence which will be more applicable to countries in that area.

It has been identified that the current study protocol by the WHO regarding antimalaria drug efficacy research does not incorporate specific outcome measure on recurrent new infections. It is, therefore, recommended that measurement of rate of recurrent new infections should be incorporated into future guidelines, and future trial investigators should make direct assessment on it.

\section{Conflict of Interests}

The authors declare that there is no conflict of interests regarding the publication of this paper.

\section{Acknowledgment}

The authors are thankful to the researchers whose studies were included in this review.

\section{References}

[1] World Health Organization, Global Malaria Program: World Malaria Report, World Health Organization, Geneva, Switzerland, 2012, http://www.who.int/malaria/publications/ world_malaria_report_2012/wmr2012_full_report.pdf.

[2] United Nations Millennium Project, Investing in Development: A Practical Plan to Achieve the Millennium Development Goals, United Nations Millennium Project, New York, NY, USA, 2005.

[3] C. J. L. Murray, L. C. Rosenfeld, S. S. Lim et al., "Global malaria mortality between 1980 and 2010: a systematic analysis," The Lancet, vol. 379, no. 9814, pp. 413-431, 2012.

[4] J. Schantz-Dunn and N. M. Nour, "Malaria and pregnancy: a global health perspective," Reviews in Obstetrics and Gynecology, vol. 2, no. 3, pp. 186-192, 2009.

[5] World Health Organization, World Malaria Report, World Health Organization, Geneva, Switzerland, 2010, http://www.who.int/malaria/world_malaria_report_ 2010/worldmalariareport2010.pdf.

[6] United Nations, The Millennium Development Goals Report, United Nations, New York, NY, USA, 2011, http://mdgs.un.org/ unsd/mdg/Resources/Static/Products/Progress2011/11-31339\%20(E)\%20MDG\%20Report\%202011_Book\%20LR.pdf.

[7] M. W. Hetzel, B. Obrist, C. Lengeler et al., "Obstacles to prompt and effective malaria treatment lead to low communitycoverage in two rural districts of Tanzania," BMC Public Health, vol. 8 , article 317, 2008.

[8] J. Chuma, T. Abuya, D. Memusi et al., "Reviewing the literature on access to prompt and effective malaria treatment in Kenya: implications for meeting the Abuja targets," Malaria Journal, vol. 8, no. 1, article 243, 2009.

[9] J. Chuma, V. Okungu, and C. Molyneux, "Barriers to prompt and effective malaria treatment among the poorest population in Kenya," Malaria Journal, vol. 9, no. 1, article 144, 2010.

[10] C. Wongsrichanalai, A. L. Pickard, W. H. Wernsdorfer, and S. R. Meshnick, "Epidemiology of drug-resistant malaria," Lancet Infectious Diseases, vol. 2, no. 4, pp. 209-218, 2002.

[11] World Health Organization, Antimalarial Drug Combination Therapy: Report of a World Health Organization Technical Consultation, World Health Organization, Geneva, Switzerland, 2001, http://whqlibdoc.who.int/hq/2001/WHO_CDS_RBM_ 2001.35.pdf.

[12] World Health Organization, Guidelines for the Treatment of Malaria, World Health Organization, Geneva, Switzerland, 2006, http://whqlibdoc.who.int/publications/ 2010/9789241547925_eng.pdf. 
[13] M. Adjuik, A. Babiker, P. Garner et al., "Artesunate combinations for treatment of malaria: meta-analysis," The Lancet, vol. 363, no. 9402, pp. 9-17, 2004.

[14] R. T. Eastman and D. A. Fidock, "Artemisinin-based combination therapies: a vital tool in efforts to eliminate malaria," Nature Reviews Microbiology, vol. 7, no. 12, pp. 864-874, 2009.

[15] E. Arinaitwe, T. G. Sandison, H. Wanzira et al., "Artemetherlumefantrine versus dihydroartemisinin-piperaquine for falciparum malaria: a longitudinal, randomized trial in young Ugandan children," Clinical Infectious Diseases, vol. 49, no. 11, pp. 1629-1637, 2009.

[16] R. N. Price, "Potential of artemisinin-based combination therapies to block malaria transmission," Journal of Infectious Diseases, vol. 207, no. 11, pp. 1627-1629, 2013.

[17] D. Sinclair, B. Zani, S. Donegan, P. Olliaro, and P. Garner, "Artemisinin-based combination therapy for treating uncomplicated malaria," Cochrane Database of Systematic Reviews, no. 3, Article ID CD007483, 2009.

[18] C. Naing, J. W. Mak, K. Aung, and J. Y. R. Wonga, "Efficacy and safety of dihydroartemisinin-piperaquine for treatment of uncomplicated plasmodium falciparum malaria in endemic countries: meta-analysis of randomised controlled studies," Transactions of the Royal Society of Tropical Medicine and Hygiene, vol. 107, no. 2, pp. 65-73, 2013.

[19] P. Olliaro, L. Pinoges, F. Checchi, M. Vaillant, and J.-P. Guthmann, "Risk associated with asymptomatic parasitaemia occurring post-antimalarial treatment," Tropical Medicine and International Health, vol. 13, no. 1, pp. 83-90, 2008.

[20] A. M. Shaukat, E. A. Gilliams, L. J. Kenefic et al., "Clinical manifestations of new versus recrudescent malaria infections following anti-malarial drug treatment," Malaria Journal, vol. 11, article 207, 2012.

[21] D. Moher, A. Liberati, J. Tetzlaff, and D. G. Altman, "Preferred reporting items for systematic reviews and meta-analyses: the PRISMA statement," PLoS Medicine, vol. 6, no. 7, Article ID e1000097, 2009.

[22] J. P. T. Higgins and S. Green, Eds., Cochrane Handbook for Systematic Reviews of Interventions, Wiley-Blackwell, Chichester, UK, 2008.

[23] L. Bax, L.-M. Yu, N. Ikeda, and K. G. M. Moons, "A systematic comparison of software dedicated to meta-analysis of causal studies," BMC Medical Research Methodology, vol. 7, article 40, 2007.

[24] S. D. Simon, Statistical Evidence in Medical Trials: What Do the Data Really Tell Us? Oxford University Press, Oxford, UK, 2006.

[25] G. H. Guyatt, A. D. Oxman, G. E. Vist et al., "GRADE: an emerging consensus on rating quality of evidence and strength of recommendations," British Medical Journal, vol. 336, no. 7650, pp. 924-926, 2008.

[26] H. Balshem, M. Helfand, H. J. Schünemann et al., "GRADE guidelines: 3. Rating the quality of evidence," Journal of Clinical Epidemiology, vol. 64, no. 4, pp. 401-406, 2011.

[27] M. Borenstein, L. V. Hedges, J. P. T. Higgins, and H. R. Rothshstein, "A basic introduction to fixed-effect and randomeffects models for meta-analysis," Research Synthesis Methods, vol. 1, no. 2, pp. 97-111, 2010.

[28] J. P. T. Higgins, S. G. Thompson, J. J. Deeks, and D. G. Altman, "Measuring inconsistency in meta-analyses," British Medical Journal, vol. 327, no. 7414, pp. 557-560, 2003.

[29] I. Adam, M. T. Salah, H. G. Eltahir, A. H. Elhassan, K. A. Elmardi, and E. M. Malik, "Dihydroartemisinin-piperaquine versus artemether-lumefantrine, in the treatment of uncomplicated Plasmodium falciparum malaria in central Sudan," Annals of Tropical Medicine and Parasitology, vol. 104, no. 4, pp. 319326, 2010.

[30] M. R. Kamya, A. Yeka, H. Bukirwa et al., "Artemetherlumefantrine versus dihydroartemisinin-piperaquine for treatment of malaria: a randomized trial," PLoS Clinical Trials, vol. 2, no. 5, article e20, 2007.

[31] P. F. Mens, P. Sawa, S. M. van Amsterdam et al., "A randomized trial to monitor the efficacy and effectiveness by QT-NASBA of artemether-lumefantrine versus dihydroartemisininpiperaquine for treatment and transmission control of uncomplicated Plasmodium falciparum malaria in western Kenya," Malaria Journal, vol. 7, article 237, 2008.

[32] Q. Bassat, M. Mulenga, H. Tinto et al., "Dihydroartemisininpiperaquine and artemether-lumefantrine for treating uncomplicated malaria in African children: a randomised, noninferiority trial," PLoS ONE, vol. 4, no. 11, Article ID e7871, 2009.

[33] W. Yavo, B. Faye, T. Kuete et al., "Multicentric assessment of the efficacy and tolerability of dihydroartemisinin-piperaquine compared to artemether-lumefantrine in the treatment of uncomplicated Plasmodium falciparum malaria in sub-Saharan Africa," Malaria Journal, vol. 10, article 198, 2011.

[34] P. Sawa, S. A. Shekalaghe, C. J. Drakeley et al., "Malaria transmission after artemether-lumefantrine and dihydroartemisinin- piperaquine: a randomized trial," Journal of Infectious Diseases, vol. 207, no. 11, pp. 1637-1645, 2013.

[35] A. Yeka, G. Dorsey, M. R. Kamya et al., "Artemetherlumefantrine versus dihydroartemisinin-piperaquine for treating uncomplicated malaria: a randomized trial to guide policy in Uganda," PLoS ONE, vol. 3, no. 6, Article ID e2390, 2008.

[36] M. Nambozi, J.-P. van Geertruyden, S. Hachizovu et al., "Safety and efficacy of dihydroartemisinin-piperaquine versus artemether-lumefantrine in the treatment of uncomplicated Plasmodium falciparum malaria in Zambian children," Malaria Journal, vol. 10, article 50, 2011.

[37] W. J. Verret, E. Arinaitwe, H. Wanzira et al., "Effect of nutritional status on response to treatment with artemisinin-based combination therapy in young Ugandan children with malaria," Antimicrobial Agents and Chemotherapy, vol. 55, no. 6, pp. 2629-2635, 2011.

[38] S. Katrak, A. Gasasira, E. Arinaitwe et al., "Safety and tolerability of artemether-lumefantrine versus dihydroartemisininpiperaquine for malaria in young HIV-infected and uninfected children," Malaria Journal, vol. 8, no. 1, article 272, 2009. 


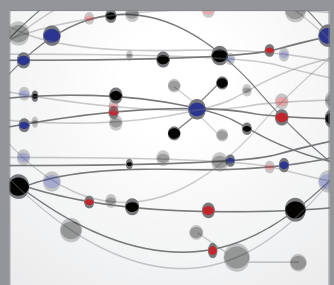

The Scientific World Journal
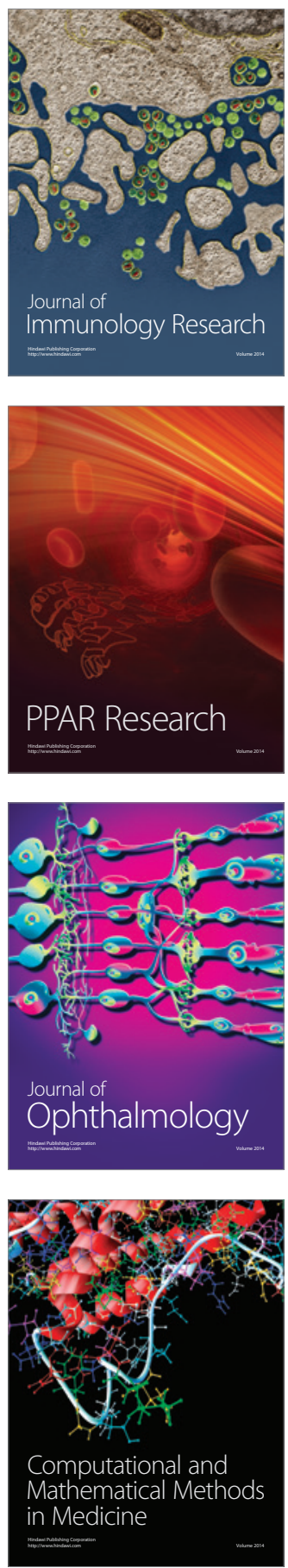

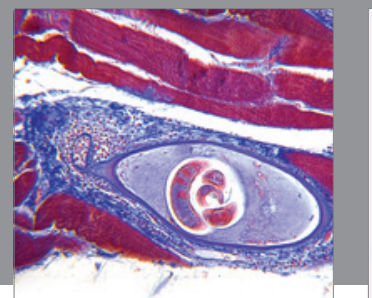

Gastroenterology

Research and Practice
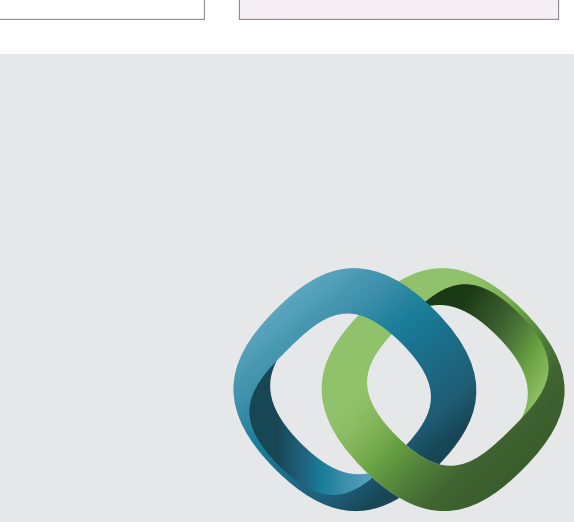

\section{Hindawi}

Submit your manuscripts at

http://www.hindawi.com
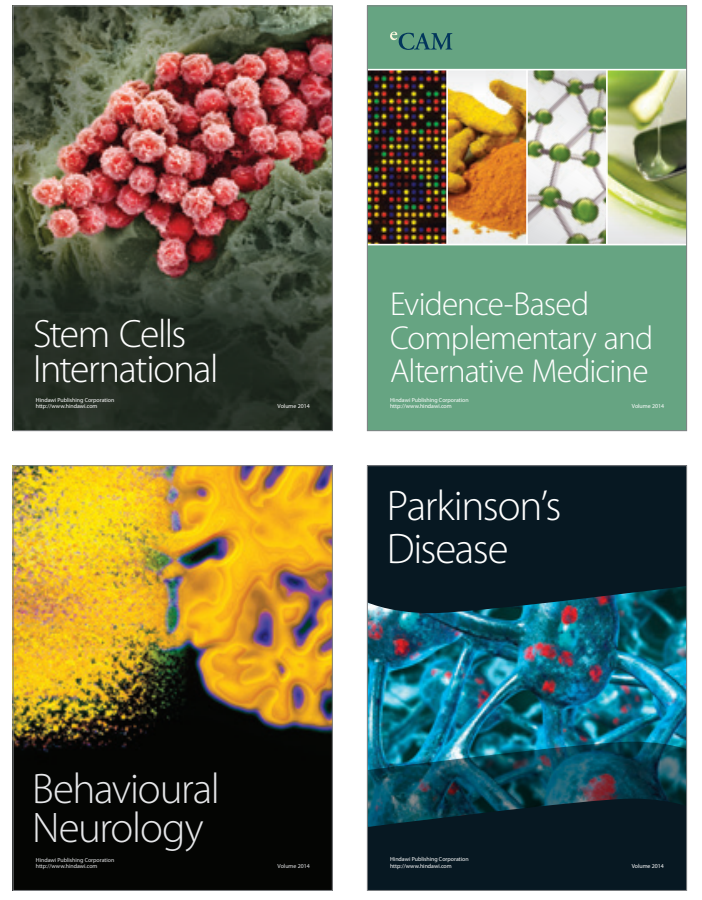
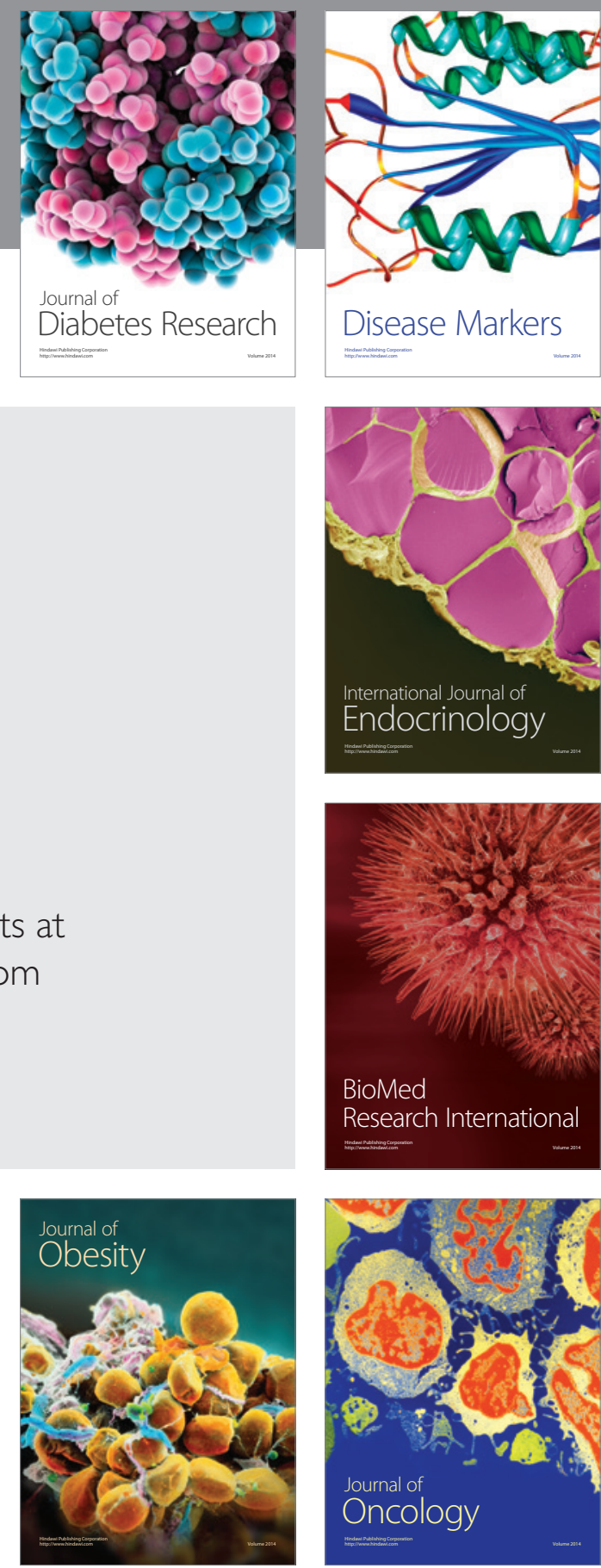

Disease Markers
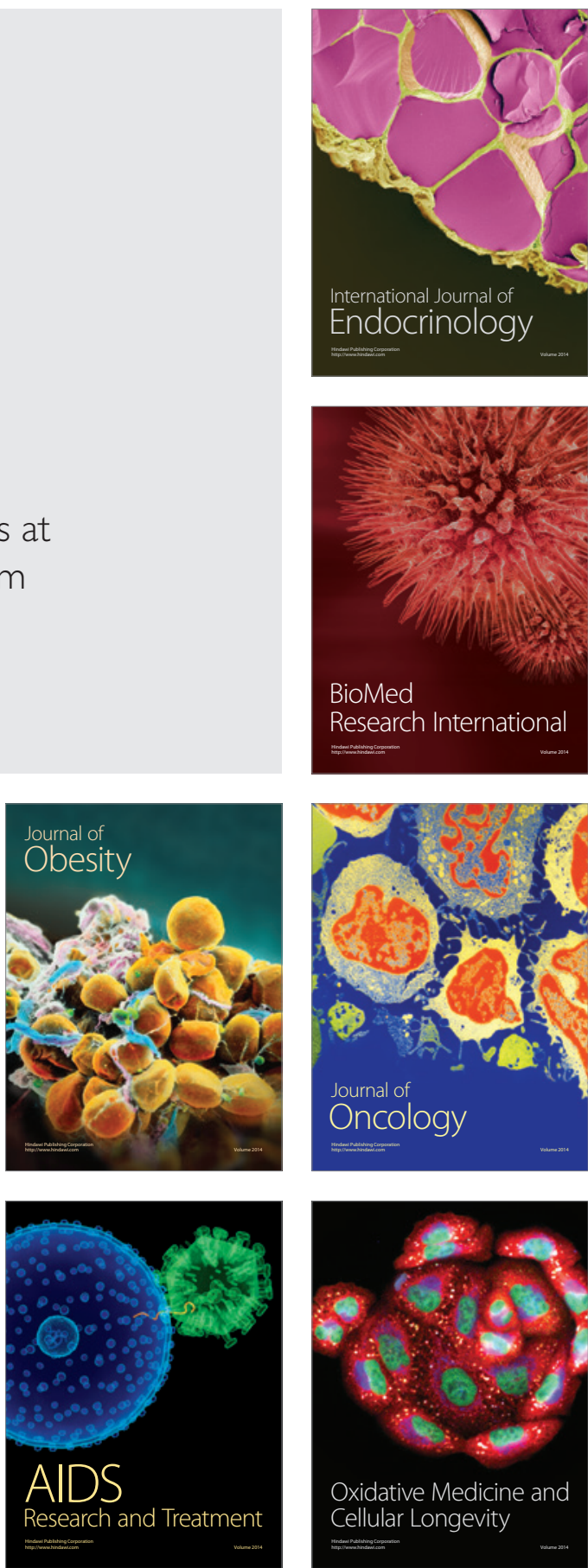